\title{
Thrombin Inhibits Intercellular Calcium Wave Propagation in Corneal Endothelial Cells by Modulation of Hemichannels and Gap Junctions
}

\author{
Catheleyne D'bondt, ${ }^{1}$ Raf Ponsaerts, ${ }^{1}$ Sangly P. Srinivas, ${ }^{2}$ Johan Vereecke, ${ }^{1}$ \\ and Bernard Himpens ${ }^{1}$
}

Purpose. Thrombin, a serine protease, breaks down the barrier integrity of corneal endothelial cells by phosphorylation of the regulatory light chain of myosin II (myosin light chain; MLC), which induces contractility of the actin cytoskeleton. This study was undertaken to investigate the effect of thrombin on gap junctional (GJIC) and paracrine (PIC) intercellular communication in cultured bovine corneal endothelial cells (BCECs). Methods. An intercellular $\mathrm{Ca}^{2+}$ wave, a form of cell-cell communication, was elicited by applying a mechanical stimulus to a single cell in a confluent monolayer. Changes in $\left[\mathrm{Ca}^{2+}\right]_{i}$ were imaged by fluorescence microscopy with a fluorescent calcium indicator, and the images were used to calculate the area reached by the $\mathrm{Ca}^{2+}$ wave (active area). GJIC was assessed by fluorescence recovery after photobleaching (FRAP). Activity of hemichannels was assayed by lucifer yellow (LY) uptake and also by adenosine triphosphate (ATP) release by using the luciferin-luciferase technique.

Results. RT-PCR showed transcripts for PAR-1 and -2 receptors, but not for PAR-4 receptors. Immunocytochemistry showed thrombin-sensitive PAR receptors as well as trypsin-sensitive PAR-2 receptors. Both thrombin and the selective PAR-1 agonist TRAP-6 reduced the active area of the $\mathrm{Ca}^{2+}$ wave. These agents also reduced the fluorescence recovery in FRAP experiments. The effect of thrombin on the $\mathrm{Ca}^{2+}$ wave was inhibited by a peptide antagonist of PAR-1, but not by a PAR- 4 antagonist. Pretreatment with ML-7 (an MLCK inhibitor), Y-27632 (a Rho kinase inhibitor) or chelerythrine (a PKC inhibitor) prevented the effect of thrombin on the $\mathrm{Ca}^{2+}$ wave. Activation of PAR-1 did not affect the $\mathrm{Ca}^{2+}$ wave propagation in cells pretreated with Gap26, which blocks hemichannels. However, PAR-1 activation decreased the active area in cells pretreated with Gap27, which inhibits gap junctions. Thrombin abolished enhancement of the $\mathrm{Ca}^{2+}$ wave propagation by ARL-67156 (inhibitor of ecto-ATPases). The effect of the PAR-1 agonists on the $\mathrm{Ca}^{2+}$ wave was not detectable in cells pretreated with exogenous apyrases.

From the ${ }^{1}$ Laboratory of Physiology, KULeuven, Leuven, Belgium; and the ${ }^{2}$ School of Optometry, Indiana University, Bloomington, Indiana.

Supported by National Eye Institute Grant EY14415 (SPS) and a Faculty Research Grant, Indiana University (SPS); FWO-Vlaanderen Grants G.0218.03 and GOA/2004/07; and IAP program 5/05 (BH, JV).

Submitted for publication July 7, 2006; revised August 25, 2006; accepted November 15, 2006

Disclosure: C. D'hondt, None; R. Ponsaerts, None; S.P. Srinivas, None; J. Vereecke, None; B. Himpens, None

The publication costs of this article were defrayed in part by page charge payment. This article must therefore be marked "advertisement" in accordance with 18 U.S.C. $\$ 1734$ solely to indicate this fact.

Corresponding author: Johan Vereecke, Laboratory of Physiology, KULeuven, Campus Gasthuisberg, O/N, B-3000 Leuven, Belgium; johan.vereecke@med.kuleuven.be.
Conclusions. Thrombin inhibits intercellular $\mathrm{Ca}^{2+}$ wave propagation in BCECs. This effect is due to activation of PAR-1 receptors and involves MLC phosphorylation by MLCK-, PKCand Rho kinase-sensitive pathways. Thrombin mainly inhibits the ATP-mediated PIC pathway, and also reduces GJIC to a lesser extent. (Invest Ophthalmol Vis Sci. 2007;48:120-133) DOI:10.1167/iovs.06-0770

$T$ he corneal endothelium is a nonregenerative monolayer ${ }^{1}$ at the posterior surface of the cornea. Its main physiological role is maintenance of the transparency of the cornea, and its decompensation leads to loss of visual acuity and is a common indication for corneal transplantation. ${ }^{2}$ For maintaining corneal transparency, the endothelium carries out hydration control of the corneal stroma by bringing about an active fluid transport into the anterior chamber, so as to balance the fluid leak into the stroma. ${ }^{3,4}$ To sustain these functions in the absence of regeneration, the corneal endothelium must possess several defense mechanisms, to withstand extracellular stresses. Intercellular communication (IC), which promotes a coordinated response from the monolayer, possibly helps in maintaining the resilience of the endothelium against extracellular stresses, such as mechanical stress during intraocular surgery or exposure to inflammatory mediators during immune rejection or uveitis. ${ }^{2,5}$

Different groups, ${ }^{6-16}$ including our own, ${ }^{17-19}$ have been investigating the mechanisms and roles of IC in the corneal endothelium and epithelium. As in many other nonexcitable cells, the corneal endothelial cells exhibit two distinct modes of IC ${ }^{17,18}$ : gap junctional IC (GJIC) and paracrine IC (PIC). In GJIC, a direct exchange of signaling molecules via gap junctions enables IC. Gap junctions are formed by the docking of two connexin $(\mathrm{Cx})$ hemichannels (also called connexons) contributed by two apposing cells. ${ }^{20}$ In contrast to GJIC, PIC does not require cell-cell apposition, as it involves release of one or more diffusible signaling molecules that bring about IC by acting on the neighboring (NB) cells. A candidate paracrine factor in the propagation of intercellular $\mathrm{Ca}^{2+}$ waves that has been well investigated in several cell types, ${ }^{11,21,22}$ including corneal endothelium, ${ }^{17,18}$ is adenosine triphosphate (ATP). Furthermore, it has been demonstrated in many cell types, including in the corneal endothelium, that the nucleotide is released through hemichannels ${ }^{17,23,24}$ and that it evokes $\mathrm{Ca}^{2+}$ wave propagation through its action on purinergic receptors. ${ }^{18,19,21}$

As reported in previous studies, corneal endothelial cells express several connexin subtypes, including the widespread Cx43. ${ }^{8,10,13,19}$ Although we are beginning to understand the expression diversity of connexins and the mechanisms underlying PIC and GJIC, not much is known about factors that influence GJIC or PIC in corneal endothelial cells. In general, GJIC is influenced by gating and also by the number of gap junctional channels. ${ }^{20}$ The latter is influenced by (1) the level of expression of connexins; (2) the assembly of connexins into 
TAble 1. Gene-Specific Primer Pairs Used for RT-PCR of Bovine PAR-1, -2 , and -4 and $\beta$-actin

\begin{tabular}{|c|c|c|c|c|}
\hline Gene & Accession No. & Primer & Sequence $\left(5^{\prime}\right.$ to $\left.3^{\prime}\right)$ & Size (bp) \\
\hline \multirow[t]{2}{*}{ PAR1 } & \multirow[t]{2}{*}{ XM_604958 } & Forward & GTGGTGTACCCCATCCAGTC & \multirow[t]{2}{*}{426} \\
\hline & & Reverse & CATGGGATCAGAGGAAAGGA & \\
\hline \multirow[t]{2}{*}{ PAR2 } & \multirow[t]{2}{*}{ XM_604897 } & Forward & CACGATCGTATTCGTGGTTG & \multirow[t]{2}{*}{360} \\
\hline & & Reverse & ATGAGCAGCCATATTCCCAG & \\
\hline \multirow[t]{2}{*}{ PAR4 } & \multirow[t]{2}{*}{ XM_583942 } & Forward & GTGCTATGTCACGACGTGCT & \multirow[t]{2}{*}{248} \\
\hline & & Reverse & CGTACAGGTGGCCGTAGAGT & \\
\hline \multirow[t]{2}{*}{$\beta$-Actin } & \multirow[t]{2}{*}{ NM_173979 } & Forward & СTCTTCCAGCCTTCCTTCCT & \multirow[t]{2}{*}{178} \\
\hline & & Reverse & GGGCAGTGATCTCTTTCTGC & \\
\hline
\end{tabular}

connexons; (3) the trafficking of connexons, resulting in the formation of hemichannels in the plasma membrane; (4) formation of gap junction channels and their accretion into plaques; and (5) internalization and degradation of hemichannels and gap junction channels. ${ }^{20}$ Trafficking of connexons and the gating of gap junction channels are known to be influenced by several factors, ${ }^{25}$ including the connexin phosphorylation status. ${ }^{26}$ Gating of the gap junction channels is also affected by several physiological factors, ${ }^{26,27}$ such as intracellular acidification, $\left[\mathrm{Ca}^{2+}\right]_{\mathrm{i}}$ and transjunctional membrane voltage. Results in several recent studies have implied that the actin cytoskeleton has an active role in the regulation of GJIC. ${ }^{20,28-33}$ It has been shown, for example, that GJIC is affected by microinjection of cells with actin antibodies ${ }^{32}$ or exposure to agents that disrupt actin or the microtubule cytoskeleton. ${ }^{29,34}$

Because GJIC requires cell-cell apposition, it is very plausible that loss of intercellular tethering forces will induce a breakdown of the gap junctions, as reported widely for tight junctions. ${ }^{35-40}$ Recent studies show that the forces affecting intercellular junctions are influenced by contractility of the actin cytoskeleton, ${ }^{36,39}$ as they oppose the intercellular tethering forces established by the adherens junctions. The contractility of the actin cytoskeleton is induced by actomyosin interaction, which is under the control of phosphorylation of the regulatory light chain of myosin II (also called myosin light chain, MLC). The level of MLC phosphorylation is dynamically regulated by myosin light chain kinase (MLCK), PKA, PKC, and Rho kinase, ${ }^{41}$ secondary to activation of several G-proteincoupled receptors (GPCRs). ${ }^{41,42}$

Much less is known about the regulation of hemichannels and PIC. ${ }^{20,24,43-45}$ In a recent study, the investigators suggested that ATP release through hemichannels is associated with depolymerization of the actin cytoskeleton. ${ }^{45}$ In the present study, the main objective was to investigate whether the altered MLC phosphorylation affects GJIC and PIC in corneal endothelial cells. Because the serine protease thrombin is well known to induce MLC phosphorylation and increase contractility of the actin cytoskeleton,,$^{35,46,47}$ we investigated the effects of this protease on GJIC and PIC in bovine corneal endothelial cells (BCECs) in the paradigm of intercellular propagation of the $\mathrm{Ca}^{2+}$ wave elicited by a mechanical stimulus. ${ }^{17,18}$ Our results show that thrombin reduces $\mathrm{Ca}^{2+}$ wave propagation, mainly by inhibiting a hemichannel-mediated ATP release-dependent PIC pathway and also by inhibiting GJIC, although to a lesser extent.

\section{Materials ANd Methods}

\section{Chemicals}

Fluo-4 AM (F14217) and 6 carboxyfluorescein diacetate (C1362) were obtained from Invitrogen-Molecular Probes (Eugene, OR); chelerythrine (C-2932), ML-7 (I-2764), thrombin (T-4648), apyrase VI (A6410), apyrase VII (A6535), ARL-67156 (6- $N, N$-diethyl- $\beta, \gamma$-dibromomethylene-
D-ATP; A265), flufenamic acid (F-9005), ATP, Triton X-100 (T-9284), rabbit serum (R-4505), luciferin-luciferase bioluminescence assay kit (FL-AAM), and lucifer yellow (L-0259) from Sigma-Aldrich (Deisenhofen, Germany); paraformaldehyde (1.04005.1000) from Merck (Darmstadt, Germany); BSA (735-078) from Roche (Vilvoorde, Belgium); TRAP-6 from Bachem (Torrance, CA); and Y-27632 (688000) from Calbiochem (La Jolla, CA). The PAR-1 antagonist peptide (sequence 3-Mpr-FCha-Cha-RKPNDK-NH2) and YD-3 are kind gifts of Marc Hoylaerts, KU Leuven.

Gap27 (SRPTEKTIFII), Gap26 (VCYDKSFPISHVR) and control (SRGGEKNVFIV) peptides were synthesized at the Laboratory of Biochemistry, KULeuven. The peptides were analyzed by reversed-phase HPLC (Waters Corp., Milford, MA), on a C18-column (Luna 5u, $250 \times$ $4.60 \mathrm{~mm}$; Phenomenex, Torrance, CA), using a linear gradient of acetonitrile-water, containing $0.06 \%$ trifluoroacetic acid (TFA). The exact sequence of the peptide was confirmed by electrospray ionization (ESI)-triple quadrupole mass spectrometry (API-3000 mass spectrometer; PE-SCIEX, Applied Biosystems, Nieuwerkerk aan den IJssel, The Netherlands). The purity of the peptide was greater than $95 \%$.

\section{Cell Culture}

Primary cultures of BCECs from fresh eyes were established as described previously. ${ }^{17-19,46,48-50}$ The growth medium consisted of Dulbecco's modified Eagle's medium (DMEM; 11960-044; InvitrogenGibco, Karlsruhe, Germany) and 10\% fetal bovine serum (F-7524; Sigma-Aldrich), 6.6\% L-glutamine (Glutamax, 35050-038; InvitrogenGibco), and 1\% antibiotic-antimycotic mixture (15240-096; InvitrogenGibco). The cells were grown at $37^{\circ} \mathrm{C}$ in a humidified atmosphere containing $5 \% \mathrm{CO}_{2}$, and those of the first, second, and third passages were harvested and seeded into two-chambered glass slides (155380, Laboratory-Tek; Nunc, Roskilde, Denmark) at a density of 165,000 cells per chamber $\left(4.2 \mathrm{~cm}^{2}\right)$. Cells were grown to confluence for 3 to 4 days before use.

\section{RT-PCR Assay for Expression of PAR Receptors}

Total RNA was extracted from BCECs (SV Total RNA Isolation System kit Z3100; Promega, Madison, WI). First-strand cDNA synthesis was performed (SuperScript II Reverse Transcriptase for RT-PCR, 11904018; Invitrogen-Gibco) with random hexamers. To amplify cDNA for PAR receptors, PCR was performed for 35 cycles $\left(94^{\circ} \mathrm{C}\right.$ for 45 seconds; $55^{\circ} \mathrm{C}$ for 30 seconds; and $72^{\circ} \mathrm{C}$ for 90 seconds [but 10 minutes in the final cycle]) with Taq DNA polymerase (18038-042; Invitrogen-Gibco) and the gene-specific primers listed in Table 1. Amplified cDNA was visualized with ethidium bromide after performing DNA gel electrophoresis ( $2 \%$ agarose) in the presence of a 50-bp DNA ladder (G4521; Promega).

\section{Expression of PAR Receptors by Immunocytochemistry}

Confluent monolayers were fixed for 10 minutes with $4 \%$ paraformaldehyde in Dulbecco's PBS (14190-091; Invitrogen-Gibco). After fixation, the BCECs were incubated for 30 minutes in a freshly made PBS 

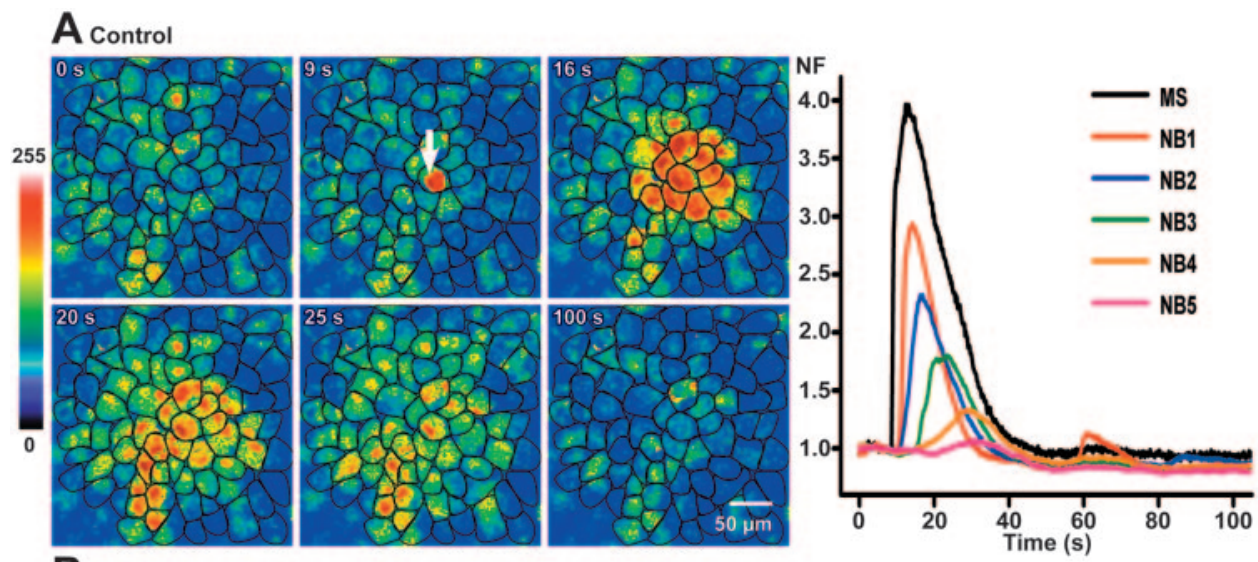

B Thrombin
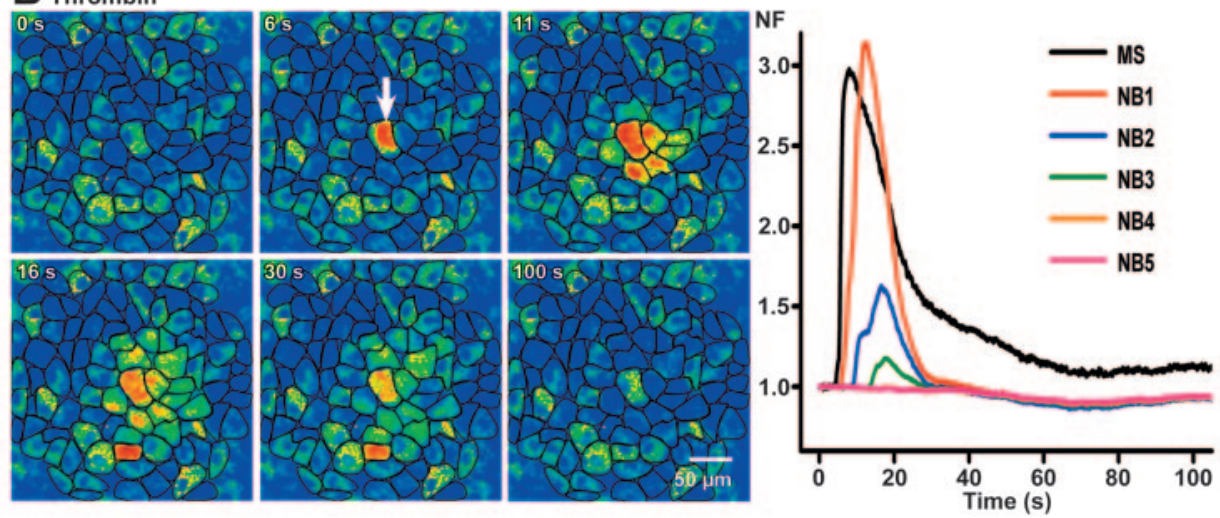

FiguRE 1. Effects of thrombin on $\mathrm{Ca}^{2+}$ wave propagation. Representative pseudocolored fluorescence images showing $\mathrm{Ca}^{2+}$ transients at different times after mechanical stimulation in BCECs. The line graphs show the time course of normalized fluorescence (NF) in the mechanically stimulated (MS) cell and the average NF in the neighboring (NB) cells layers 1 to 5 (NB1-NB5). The first image shows the fluorescence intensities before stimulation. White arrow: MS cell. (A) Control conditions: $\mathrm{a} \mathrm{Ca}^{2+}$ wave propagates to five NB cell layers. The total area of cells reached by the wave (AA) was $63,800 \mu \mathrm{m}^{2}$. (B) Effects of thrombin: thrombin (2 $\mathrm{U} / \mathrm{mL}$ for 5 minutes) reduces the spread of the wave to three layers and the AA to $15,800 \mu \mathrm{m}^{2}$. solution containing 3\% BSA and 10\% goat serum. They were rinsed with PBS after each treatment. After blocking, the cells were incubated overnight at $4{ }^{\circ} \mathrm{C}$ with a rabbit polyclonal antibody directed against the thrombin receptor (ab13398; Abcam PLC, Cambridge, UK) or PAR-2 (ab13097; Abcam PLC). The secondary antibody was goat anti-rabbit IgG labeled with FITC (ab6717; Abcam PLC). The negative controls were obtained in identical conditions, but the cells were not exposed to the primary antibody. Finally, the cells were visualized with a confocal microscope (LSM510; Carl Zeiss Meditec, GmbH, Jena, Germany). The 488-nm line of the Argon laser was used for excitation. Emission was recorded via a long-pass filter at $505 \mathrm{~nm}$.

\section{Fluorescence Recovery after Photobleaching}

We have described the FRAP (fluorescence recovery after photobleaching) protocol in BCECs previously ${ }^{17-19}$ Briefly, cells were loaded with the $\mathrm{Ca}^{2+}$-insensitive dye 6-carboxyfluorescein diacetate $(10 \mu \mathrm{M})$ for 5 minutes at room temperature, and fluorescence recovery was measured with the confocal microscope. For recording fluorescence recovery, the dye was excited at $488 \mathrm{~nm}$ and its emission was recorded at $530 \mathrm{~nm}$. A neutral-density filter was also used to minimize photobleaching. Before photobleaching, a polygon was drawn around a cell chosen for bleaching, and two images were obtained. The chosen cell was then exposed to 50 scans with the laser at $95 \%$ intensity, and the recovery of fluorescence in the bleached cell was measured every 10 seconds over a period of 5 minutes. The decrease of fluorescence in a square region of interest widely distant from the bleached cell was measured as a reference for correction for bleaching due to the excitation light used for fluorescence detection while recording fluorescence recovery. After correction for background bleaching, recovery of fluorescence in the bleached cell at 3 minutes was compared with that of the prebleach scan, and the percentage recovery was calculated.

\section{Mechanical Stimulation for Inducing a $\mathrm{Ca}^{2+}$ Wave}

The protocol for point mechanical stimulation of a single cell has been described in our previous study. ${ }^{17-19}$ It consists of bringing about an acute deformation of the chosen cell by briefly touching less than $1 \%$ of its cell membrane with a glass micropipette (tip diameter $<1 \mu \mathrm{m}$ ) coupled to a piezoelectric crystal (Piezo device P-280, Amplifier-E463; PI Polytech, Karlsruhe, Germany) mounted on a micromanipulator.

\section{Measurement of $\left[\mathrm{Ca}^{2+}\right]_{\mathbf{i}}$}

The $\mathrm{Ca}^{2+}$ wave propagation was assayed by imaging $\left[\mathrm{Ca}^{2+}\right]_{\mathrm{i}}$ as described previously. ${ }^{17-19}$ Cells were loaded with the $\mathrm{Ca}^{2+}$-sensitive dye, Fluo-4 AM (10 $\mu \mathrm{M}$; Invitrogen-Molecular Probes) for 30 minutes at $37^{\circ} \mathrm{C}$. The dye was excited at $488 \mathrm{~nm}$, and its fluorescence emission was collected at $530 \mathrm{~nm}$. Spatial changes in $\left[\mathrm{Ca}^{2+}\right]_{\mathrm{i}}$ after point mechanical stimulation were measured with the confocal microscope (LSM510; Carl Zeiss Meditec, GmbH) equipped with a $40 \times$ objective (Air, 1.2 NA), but in experiments with ARL-67156, a $10 \times$ objective (Air, $0.3 \mathrm{NA}$ ) was used. Images were collected and stored on a personal computer. Polygonal regions of interest (ROIs) were drawn to define the borders of each cell. A cell (called the mechanically stimulated (MS) cell) was selected for point of mechanical stimulation. The NB cells immediately surrounding the MS cell were defined as NB cell layer 1 (NB1), the ones immediately surrounding the NB1 cells was defined as NB cell layer 2 (NB2), and so on. Fluorescence was averaged over the area of each ROI. Normalized fluorescence (NF) was then obtained by dividing the fluorescence by the average fluorescence before point mechanical stimulation. Intercellular propagation of the $\mathrm{Ca}^{2+}$ wave was characterized by maximum normalized fluorescence (NF), and percentage of responsive cells (\%RC), as well as the total surface area of responsive cells (active area, $\mathrm{AA}$ ) with $\mathrm{NF} \geq 1.1$.

Response to exogenously applied ATP after pretreatment with thrombin was also characterized by using Fluo- 4 as just described, but 
the normalized fluorescence averaged over all cells in the field of view was used as a measure of $\left[\mathrm{Ca}^{2+}\right]_{\mathrm{i}}$.

\section{Measurement of ATP Release}

ATP release, resulting from mechanical stimulation on the confocal microscope, was followed-up using the luciferin-luciferase bioluminescence protocol. One hundred microliters was sampled out from the $500 \mu \mathrm{L}$ bathing solution covering the cells and taken to a custom-built photon-counting setup to measure the luminescence, as described previously. ${ }^{17,51}$ Briefly, photons emitted as a result of the oxidation of luciferin in the presence of ATP and $\mathrm{O}_{2}$ and catalyzed by luciferase were detected by a photon-counting photomultiplier tube (H7360-01; Hamamatsu Photonics, Hamamatsu City, Japan). Voltage pulses from the photomultiplier module were counted with a high-speed counter (PCI-6602; National Instruments, Austin, Texas, USA). Dark count of the photomultiplier tube was less than 80 counts/second.

\section{Lucifer Yellow Uptake Assay}

Cells grown to confluence on chamber slides were incubated in a $\mathrm{Ca}^{2+}$-rich PBS containing the drug of interest for 30 minutes. Cells were then exposed to PBS containing $2 \mathrm{mM}$ EGTA and $2.5 \%$ Lucifer yellow (LY) for 5 minutes in the continued presence of the drug. After a brief wash with $\mathrm{Ca}^{2+}$-containing PBS, LY fluorescence $\left(\lambda_{\mathrm{ex}}=488\right.$ $\mathrm{nm} ; \lambda_{\mathrm{em}}=530 \mathrm{~nm}$ ) from cells was imaged with the confocal microscope (LSM510; Carl Zeiss Meditec, GmbH).

\section{Data Analysis}

One-way ANOVA was used to compare the mean results of different treatments, whereas unpaired tests were used to compare the results of experiments with a single treatment and a single control (Prism 4.0 for Windows; GraphPad Software Inc., San Diego, CA). $P<0.05$ was considered statistically significant. Data are expressed as the mean \pm SEM. $N$ is the number of independent experiments (the number of MS cells), whereas $n$ represents the total number of responsive cells.

\section{Results}

\section{Effects of Thrombin on $\mathrm{Ca}^{2+}$ Wave Propagation}

In control conditions, the MS cell showed a transient $\left[\mathrm{Ca}^{2+}\right]_{\mathrm{i}}$ increase that originated at the point of stimulation and spread out to the NB cells in a wavelike manner, as shown by the fluorescence images in Figure $1 \mathrm{~A} . \mathrm{Ca}^{2+}$ transients were observed up to approximately four to six cell layers away from the MS cell. The line graph (Fig. 1A, right) shows the time course of the $\mathrm{Ca}^{2+}$ transients (represented as NF values) in the MS cell and in the NB cell layers one to five. The figure also shows that the normalized fluorescence decreased, whereas the time delay for the onset of the rise in $\left[\mathrm{Ca}^{2+}\right]_{i}$ was lengthened, with increasing distance from the MS cell. Cells subjected to mechanical stimulation after incubation with thrombin $(2 \mathrm{U} / \mathrm{mL})$ for 5 minutes, also show intercellular propagation of the $\mathrm{Ca}^{2+}$ wave, but the spread of the wave is limited to only approximately two to four cell layers (Fig. 1B). A quantitative summary of similar experiments is provided in Figure 2 and Table 2. The normalized fluorescence and the percentage of responsive cells (\%RC) decreases as a function of the distance of the cell layer from the MS cell. In the presence of thrombin, this spatial decline is accelerated. The AA, a measure of efficacy of the $\mathrm{Ca}^{2+}$ wave, was $51,400 \pm 1,300 \mu \mathrm{m}^{2}(N=140)$ under control conditions and was reduced by $\sim 70 \%$ to $15,000 \pm$ $1,000 \mu \mathrm{m}^{2}(N=140)$ in the presence of thrombin in contemporaneous experiments (Fig. 2C). Therefore, the results in Figures 1 and 2 demonstrate that thrombin significantly inhibits the intercellular propagation of $\mathrm{Ca}^{2+}$ waves in BCECs.
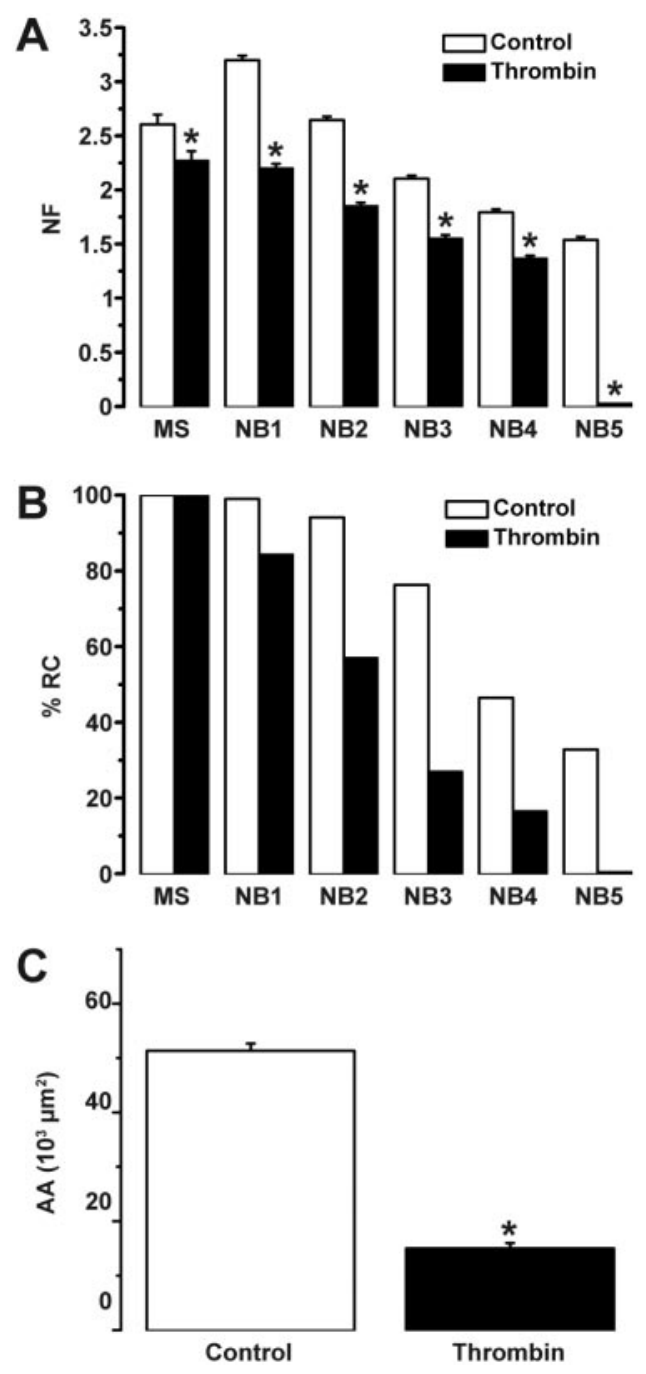

FIGURE 2. Quantification of the spread of the $\mathrm{Ca}^{2+}$ wave in control conditions and in the presence of thrombin. (A) Average NF in the MS cell and in NB cell layers 1 to 5 in control conditions and in the presence of thrombin (2 U/mL for 5 minutes). (B) Percentage of responsive cells (\%RC) in MS and NB1 to NB5 in control conditions and in the presence of thrombin. (C) AA in the presence of thrombin versus control conditions. Data represent average values from 140 contemporaneous experiments. ${ }^{*} P<0.001$ for thrombin versus control.

Because the effect of thrombin on the AA after mechanical stimulation could be due to several factors other than propagation of the $\mathrm{Ca}^{2+}$ wave (e.g., thrombin could have emptied $\mathrm{Ca}^{2+}$ stores or have an effect on ATP-mediated IP3 release), we also measured the $\mathrm{Ca}^{2+}$ rise in response to exogenous ATP (10 $\mu \mathrm{M})$ in cells pretreated with thrombin and in untreated cells. The peak increase in $\left[\mathrm{Ca}^{2+}\right]_{i}$ in thrombin-treated cells on exposure to ATP was not significantly different from that in untreated cells $(N=25 ; P<0.05)$, suggesting that the effect of thrombin is not due to an effect on $\mathrm{P} 2$ receptor-mediated signaling.

\section{Identity of Receptors Involved in the Effects of Thrombin}

It is known that thrombin activates GPCRs-more specifically, proteinase-activated receptors (PAR family of receptors). ${ }^{52}$ To date, four PAR receptors have been described, and most cell types express multiple PAR receptors. ${ }^{52-55}$ To find the identity 
TABle 2. Average Maximum NF, Percentage Responsive Cells, and AA in the MS and NB Layers during Mechanical Stimulation in Control Conditions and after Treatment with Thrombin

\begin{tabular}{|c|c|c|c|c|c|c|c|}
\hline & MS & NB1 & NB2 & NB3 & NB4 & NB5 & $\mathbf{A A}\left(\mu \mathbf{m}^{2}\right)$ \\
\hline \multicolumn{8}{|l|}{ Control } \\
\hline $\mathrm{NF} \pm \mathrm{SEM}$ & $2.61 \pm 0.09$ & $3.20 \pm 0.04$ & $2.64 \pm 0.03$ & $2.11 \pm 0.03$ & $1.79 \pm 0.03$ & $1.54 \pm 0.03$ & $51,366 \pm 1,294$ \\
\hline$\% \mathrm{RC}$ & 100 & 99 & 94 & 76 & 46 & 33 & \\
\hline$n$ & 49 & 340 & 654 & 834 & 646 & 423 & \\
\hline \multicolumn{8}{|l|}{ Thrombin } \\
\hline $\mathrm{NF} \pm \mathrm{SEM}$ & $2.27 \pm 0.09^{*}$ & $2.20 \pm 0.04^{*}$ & $1.85 \pm 0.03^{*}$ & $1.55 \pm 0.03^{*}$ & $1.37 \pm 0.02^{*}$ & $0.00 \pm 0.00^{*}$ & $15,013 \pm 993$ \\
\hline$\% \mathrm{RC}$ & 100 & 84 & 57 & 27 & 17 & 0 & \\
\hline$n$ & 49 & 380 & 568 & 298 & 174 & 0 & \\
\hline
\end{tabular}

Data were collected during mechanical stimulation in control conditions and in cells treated with thrombin (2 U/mL for $5 \mathrm{~min})$.

${ }^{*} P<0.05$ versus control.

of PAR receptors expressed in BCECs, we performed RT-PCR and immunocytochemistry. RT-PCR demonstrated expression of mRNA for PAR-1 and -2 in BCECs, but not PAR-4 (Fig. 3A). Immunocytochemistry was performed to confirm the expression using an antithrombin receptor antibody as well as a PAR-2-specific antibody. As shown in Figure 3, both thrombinsensitive receptors (Fig. 3C) and PAR-2 receptors (Fig. 3D) are very well expressed on the cell surface. In consistence with the expression of PAR-1 and -2 receptors and their coupling to $\mathrm{G}_{\alpha \mathrm{q} / 11},{ }^{52-55}$ acute exposure to thrombin as well as trypsin (1 $\mu \mathrm{M})$ produced a transient increase in $\left[\mathrm{Ca}^{2+}\right]_{\mathrm{i}}(\mathrm{NF}=2.08 \pm$ $0.06 ; N=25 ; \mathrm{NF}=2.43 \pm 0.12 ; N=10$, respectively).

We also investigated the identity of the PAR receptors involved in the inhibitory effect of thrombin on the intercellular propagation of the $\mathrm{Ca}^{2+}$ wave, using PAR agonists and antagonists (Fig. 4). Pretreatment with TRAP-6 (thrombin re- ceptor-activator peptide- 6 with the sequence SFLLRN; $10 \mu \mathrm{M}$ for 30 minutes), a selective PAR-1 activating peptide, also reduced the AA from $62,000 \pm 2,800 \mu \mathrm{m}^{2}(N=50)$ in control conditions to 26,000 $\pm 3,200 \mu \mathrm{m}^{2}(P<0.001 ; N=50$; Fig. $4 A)$. In accordance with this PAR-1-mediated effect, thrombin failed to induce reduction in the AA in the presence of a PAR-1 antagonist (a mimetic peptide with the sequence 3-Mpr-FChaCha-RKPNDK-NH2 $2^{56} 10 \mu \mathrm{M}$ for 30 minutes; $P<0.001 ; N=20$; Fig. 4B). We also investigated possible involvement of PAR-4 receptors using the indazole derivative YD-3, a selective PAR-4 antagonist. ${ }^{57}$ On pretreatment with YD-3 (50 $\mu \mathrm{M}$ for $30 \mathrm{~min}$ utes), thrombin caused a significant reduction of the AA $(P<$ $0.001 ; N=20$ ) similar to the reduction caused by thrombin in the absence of the antagonist. Therefore, we conclude that PAR- 4 receptors do not contribute to the observed effect of thrombin on the $\mathrm{Ca}^{2+}$ wave propagation. To determine the
A

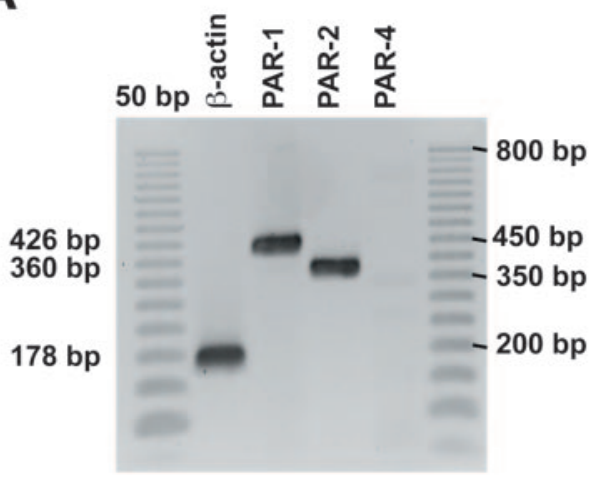

C

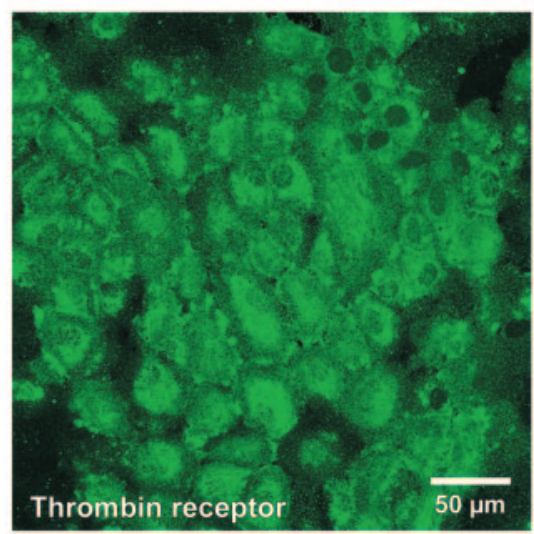

B

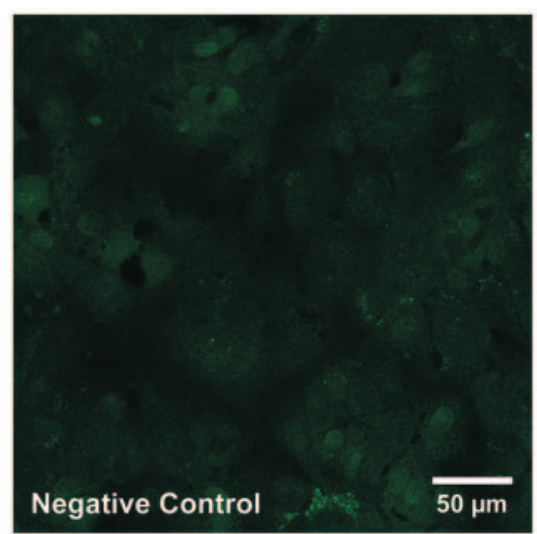

D

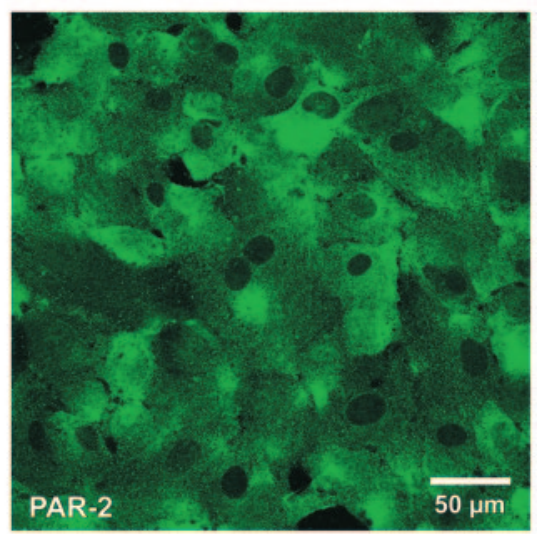

FiguRE 3. Expression of PAR family receptors. (A) RT-PCR results for PAR-1, -2 , and -4 receptors. PCR amplification products for $\beta$-actin (178 bp), PAR-1 (426 bp), and PAR-2 (360 $\mathrm{bp}$ ), as visualized on an ethidium bromide-stained agarose gel. Expression of PAR-4 (248 bp) could not be detected. (B) Immunofluorescent detection of PAR-1 in cultured BCECs. A negative control is obtained by exclusion of the primary antibodies during staining procedures. Because the secondary antibody (a FITC-conjugated antibody) is the same for PAR-1 and -2 staining, only one negative control is presented. (C) Positive staining for the thrombin receptor is clearly shown. (D) Positive staining for PAR-2 is clearly shown. 

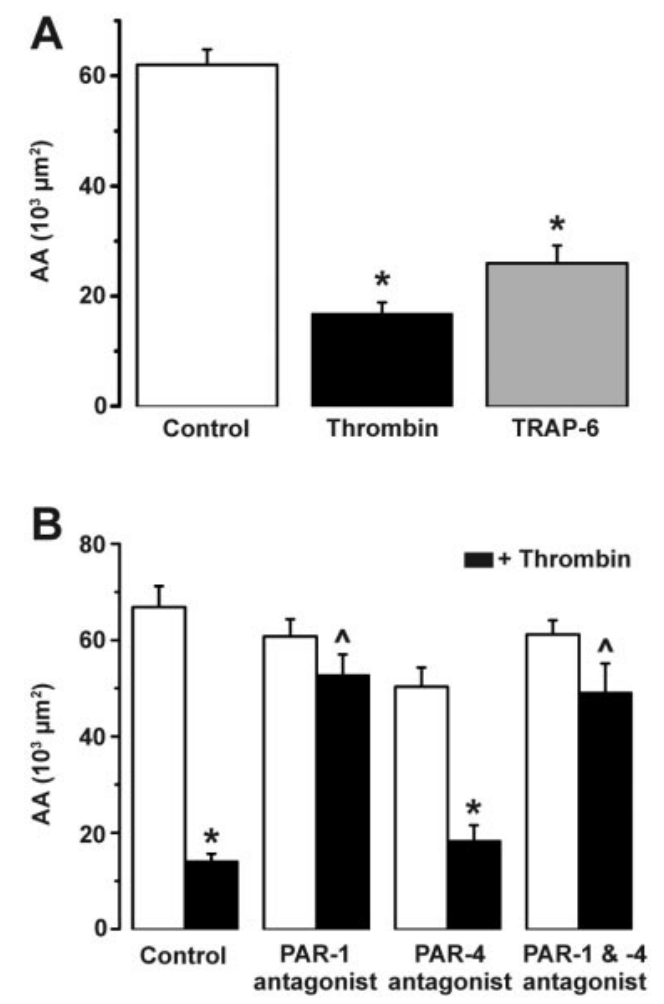

FIGURE 4. Effect of the thrombin receptor agonists and antagonists on the AA of the $\mathrm{Ca}^{2+}$ wave. (A) Effect of thrombin $(\mathbf{\square} ; 2 \mathrm{U} / \mathrm{mL}$ for 5 minutes; $N=50$ ) and the PAR-1 agonist TRAP-6 (濇; $10 \mu \mathrm{M}$ for 30 minutes; $N=50$ ) on AA. ( $\square$ ) AA in the absence of the PAR-1 agonist. (B) Effect of thrombin on $\mathrm{Ca}^{2+}$ wave propagation in control condition, in the presence of a PAR-1 antagonist peptide ( $10 \mu \mathrm{M}$ for 30 minutes; $N=20)$, in presence of the PAR- 4 antagonist YD-3 $(50 \mu \mathrm{M}$ for 30 minutes; $N=20$ ) or in the presence of a combination of YD-3 and PAR-1 antagonist peptide. ${ }^{*} P<0.001$ for comparison between AA in the presence of thrombin versus its control in contemporaneous experiments (i.e., $\square$ vs. $\square$ in each condition). ${ }^{\wedge} P<0.001$ for comparison of AA in cells treated with thrombin with and without PAR antagonist (i.e., comparison of $\boldsymbol{\square}$ in each condition with $\boldsymbol{\square}$ in the control condition).

potential contribution of other thrombin-sensitive receptors or proteolytic effects on proteins other than PAR-1, we investigated the $\mathrm{Ca}^{2+}$ wave propagation after treating the cells with a combination of the PAR-1 and -4 antagonists. Under these conditions, thrombin failed to produce a decrease in the AA (Fig. 4B), excluding a significant contribution of other receptors to the inhibitory effect of thrombin on the $\mathrm{Ca}^{2+}$ wave. Exposure to the PAR-2 agonist trypsin ( $1 \mu \mathrm{M}$ for 5 minutes) had no significant influence on $\mathrm{Ca}^{2+}$ wave propagation (AA $55,100 \pm 1,700 \mu \mathrm{m}^{2}$ in the presence of trypsin versus $59,400 \pm 4,500 \mu \mathrm{m}^{2}$ in the control $(N=25)$. Based on these observations, we conclude that the effect of thrombin on the $\mathrm{Ca}^{2+}$ wave propagation in BCECs is mediated through PAR-1 receptors.

\section{Signal Transduction Underlying the Effects of Thrombin}

It has been demonstrated that exposure of BCECs to thrombin increases MLC phosphorylation, which enhances contractility of the actin cytoskeleton and breaks down the barrier integrity. ${ }^{46,48,49}$ MLC phosphorylation is driven by MLCK, whereas its dephosphorylation is brought about by myosin light chain phosphatase (MLCP). ${ }^{41,42}$ MLCK can be activated by thrombin, because PAR-1 is coupled to $\mathrm{G}_{\alpha \mathrm{q} / 11}$, which results in $\mathrm{Ca}^{2+}$ release and hence $\mathrm{Ca}^{2+}$-calmodulin binding to the kinase. PAR-1 receptors also activate PKC via $G_{\alpha q / 11}$, whereas they activate Rho kinase via $\mathrm{G}_{\alpha 12 / 13}$; these two pathways contribute toward inactivation of MLCP. ${ }^{41,42}$ The transduction of the thrombin effect on MLC phosphorylation can thus occur via two pathways-namely, inhibition of the MLCP or stimulation of the MLCK. ${ }^{46,48,49} \mathrm{We}$, therefore, performed experiments to investigate whether thrombin exerts its effect on the $\mathrm{Ca}^{2+}$ wave propagation through the same transduction cascade that decreases the barrier integrity.

Pretreatment with MLCK inhibitor ML-7 (10 $\mu \mathrm{M}$ for 30 minutes) significantly suppressed the effect of thrombin or TRAP-6 on the propagation of the $\mathrm{Ca}^{2+}$ wave $(P<0.001 ; N=$ 25; Fig. 5A). Pretreatment with the Rho kinase inhibitor $\mathrm{Y}-27632$ (10 $\mu \mathrm{M}$ for 30 minutes) partially suppressed the effect of thrombin or TRAP- 6 on the $\mathrm{Ca}^{2+}$ wave propagation $(P<$ 0.05; $N=25$; Fig. 5B). Pretreatment with the PKC inhibitor chelerythrine ( $5 \mu \mathrm{M}$ for 30 minutes) also significantly suppressed the effect of thrombin on the propagation of the $\mathrm{Ca}^{2+}$ wave $(P<0.05 ; N=25$; Fig. $5 \mathrm{C})$. The AA in the presence of a combination of Y-27632 plus chelerythrine, or in the presence of a combination of ML-7+Y-27632+ chelerythrine, was also not significantly affected by thrombin $(N=25$; Fig. $5 \mathrm{C})$. The absence of a significant effect of thrombin in the presence of the combination of the three protein kinase inhibitors provides evidence that the major pathways for the effect of thrombin on the AA are via MLCK, Rho kinase, and PKC.

\section{Effects of Thrombin on GJIC and PIC}

Previous studies in our laboratory demonstrated that in BCECs, both GJIC and PIC contribute to the $\mathrm{Ca}^{2+}$ wave evoked in response to mechanical stimulation. ${ }^{17,18}$ However, it was shown that the predominant mechanism underlying the $\mathrm{Ca}^{2+}$ wave propagation is PIC mediated through ATP release. To understand the mechanism of action of thrombin, we investigated the relative inhibition of GJIC and PIC in response to the protease.

FRAP Experiments. Intercellular transfer of hydrophilic dyes (e.g., carboxyfluorescein) in the FRAP protocol indicates functional GJIC. ${ }^{19}$ As shown in Figure 6A, pretreatment with thrombin resulted in a significant but limited decrease in the recovery of fluorescence in the bleached cell. Thus, 3 minutes after bleaching, the recovery of fluorescence was reduced by $15 \%$ in the presence of thrombin. This reduction of the fluorescence recovery by thrombin was inhibited by ML-7 (10 $\mu \mathrm{M}$ for 30 minutes) as well as by Y-27632 (10 $\mu \mathrm{M}$ for 30 minutes) or chelerythrine ( $5 \mu \mathrm{M}$ for 30 minutes; Figs. 6B-D). The limited effect of thrombin on GJIC, which contrasts with the marked reduction of AA (decrease by $\sim 70 \%$; Fig. 2 , Table 2 ), suggests that the effect of thrombin on the $\mathrm{Ca}^{2+}$ wave propagation is mainly mediated via PIC. Furthermore, the effects of the inhibitors provide evidence that the effect of thrombin on GJIC is associated with pathways that affect MLC phosphorylation.

Effects of Connexin Mimetic Peptides. In our previous studies, we used connexin mimetic peptides (Gap27 and Gap26) to distinguish relative contributions of GJIC and PIC to intercellular $\mathrm{Ca}^{2+}$ wave propagation after mechanical stimulation. ${ }^{17,18}$ We used the same peptides and followed identical treatment protocols to explore the effect of thrombin on the two mechanisms. Gap27 was shown to decrease significantly the propagation of the $\mathrm{Ca}^{2+}$ wave in BCECs via inhibition of gap junction channels. ${ }^{19}$ As shown in Figure $7 \mathrm{~A}$, pretreatment with Gap27 (300 $\mu \mathrm{M}$ for 30 minutes) led to a reduction in the AA $(P<0.001 ; N=40)$. Exposure to thrombin led to a further decrease $(P<0.05 ; N=40 ;$ Fig. $7 \mathrm{~A})$. This observation suggests 

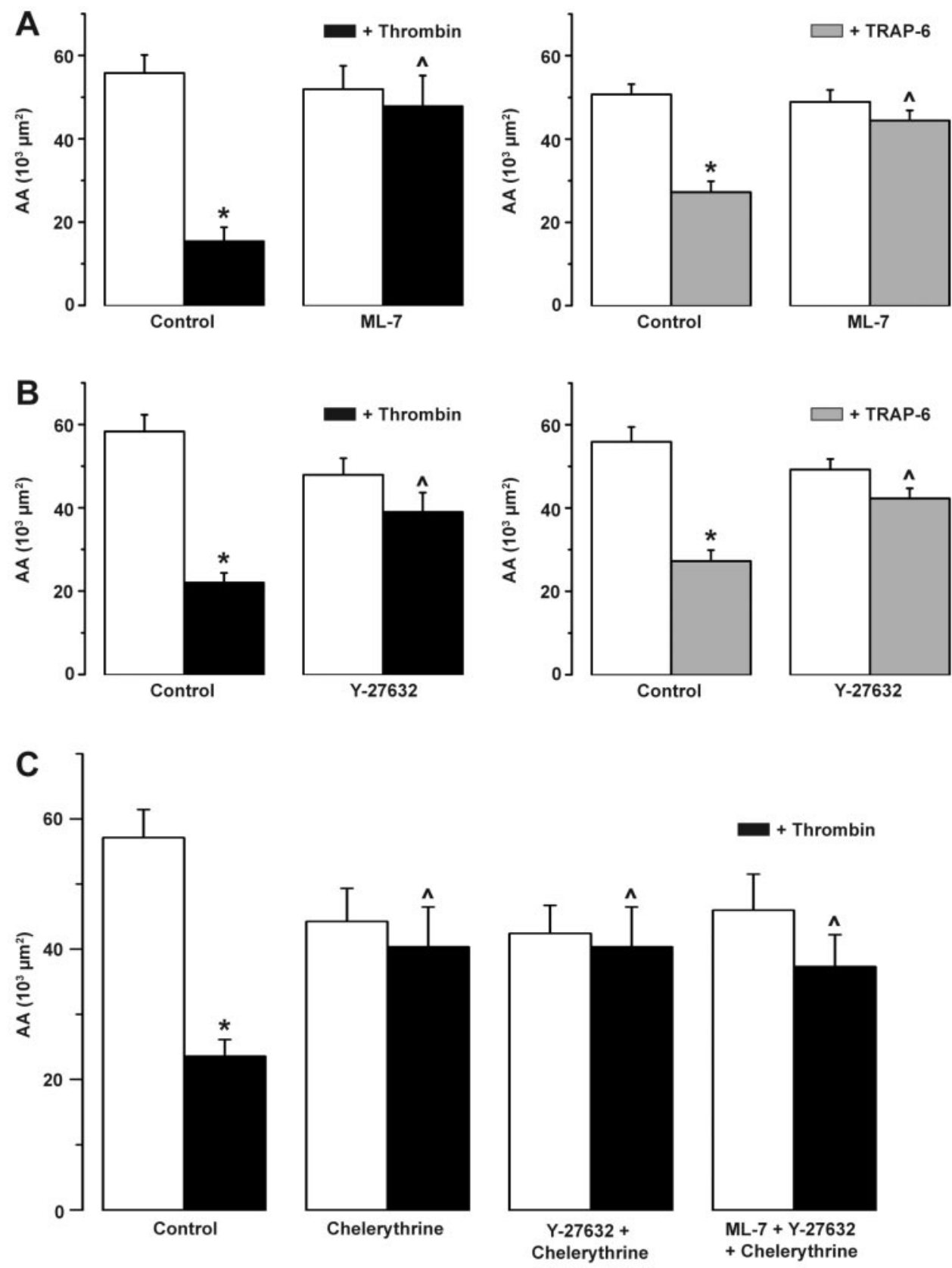

FIGURE 5. Effect of thrombin on the AA in the presence of inhibitors of MLCK, Rho kinase, and PKC. AA in cells that were treated with thrombin ( $2 \mathrm{U} / \mathrm{mL}$ for 5 minutes) or TRAP-6 (10 $\mu \mathrm{M}$ for 30 minutes) after preincubation with protein kinase inhibitors for 30 minutes $(N=25)$. ( $\square) \mathrm{AA}$ in the absence of the PAR-1 agonist. (A) ML-7 $(10 \mu \mathrm{M})$, a selective inhibitor of MLCK. (B) Rho kinase inhibitor Y-27632 (10 $\mu \mathrm{M})$. (C) Chelerythrine $(5 \mu \mathrm{M})$, a PKC inhibitor and its combination with Y-27632 and ML-7. ${ }^{*} P<0.001$ for comparison between $\mathrm{AA}$ in the presence versus the absence of the PAR-1 agonist (i.e., com-

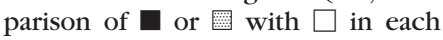
condition). ${ }^{\wedge} \mathrm{P}<0.05$ for comparison between AA in the presence versus absence of the protein kinase inhibitors (i.e., comparison of $\boldsymbol{\square}$ in each condition with $\boldsymbol{\text { in }}$ the control condition).

that thrombin has an effect on wave propagation that is insensitive to Gap27. The presence of an inactive control peptide did not influence the effect of thrombin. We obtained similar findings when TRAP-6 was used instead of thrombin (Fig. 7B). These results provide additional evidence that thrombin and TRAP-6 exert their major effects on $\mathrm{Ca}^{2+}$ wave propagation through inhibition of PIC.

The connexin-mimetic peptide Gap26, which has been demonstrated to block connexin hemichannels, ${ }^{17,19}$ significantly reduces the propagation of the $\mathrm{Ca}^{2+}$ wave in BCECs. ${ }^{17}$ As shown in Figure 7A, pretreatment with Gap26 (300 $\mu \mathrm{M}$ for 30 minutes) reduced the AA. Exposure to thrombin after pretreatment of the cells with Gap26 did not cause a further reduction of the AA. Similar effects were obtained using TRAP-6 (Fig. 7B). These findings provide evidence that thrombin exerts an effect on PIC that is due to inhibition of connexin hemichannels.

The presence of Gap27 and Gap26, did not affect the activity of thrombin as measured by thrombin time. Based on the thrombin recognition and cleavage motif ${ }^{52,55}$ and on the amino acid sequences of Gap27 and Gap26, proteolysis of the peptides is not expected.

Effects of Stimulated or Inhibited Extracellular ATP Hydrolysis. Because PIC in the endothelium is largely through ATP release, ${ }^{17,18}$ inhibition of ectonucleotidases, known to be expressed in the endothelium, ${ }^{18,48,49}$ results in strong enhancement of the wave propagation, as has been demonstrated previously in BCECs. ${ }^{17,18}$ As shown in Figure 8A, exposure to the ectonucleotidase inhibitor ARL-67156 (100 $\mu \mathrm{M}$ for $30 \mathrm{~min}$ utes) increased the AA from 55,500 $\pm 3,700$ to $258,300 \pm$ $2,300 \mu \mathrm{m}^{2}(P<0.001 ; N=20)$. Furthermore, the same figure shows that this large AA was reduced to $33,500 \pm 8,000 \mu \mathrm{m}^{2}$ $(P<0.001 ; N=20)$ in the presence of thrombin. Thus, the very pronounced enhancement of the $\mathrm{Ca}^{2+}$ wave produced by 
Figure 6. Gap junctional communication analysis by FRAP. Cells were loaded with carboxyfluorescein. Recovery of the fluorescence after photobleaching (corrected for background bleaching) of a single cell plotted as function of time after bleaching. (A) BCECs pretreated with thrombin versus control conditions. Three minutes after bleaching, a recovery of $68 \% \pm 0.97 \%$ was noted in control conditions whereas, in the presence of thrombin, $58 \% \pm$ $1.29 \%$ of the fluorescence was recovered $(P<0.001, N=190)$. (B-D) Effects of thrombin in the presence or absence of ML-7 $(10 \mu \mathrm{M} ; N=70)$, Y27632 $(10 \mu \mathrm{M} ; N=70)$ or chelerythrine ( $5 \mu \mathrm{M} ; N=25$ ) applied for 30 minutes. $P<0.001$ for each combination of inhibitor plus thrombin versus thrombin alone.
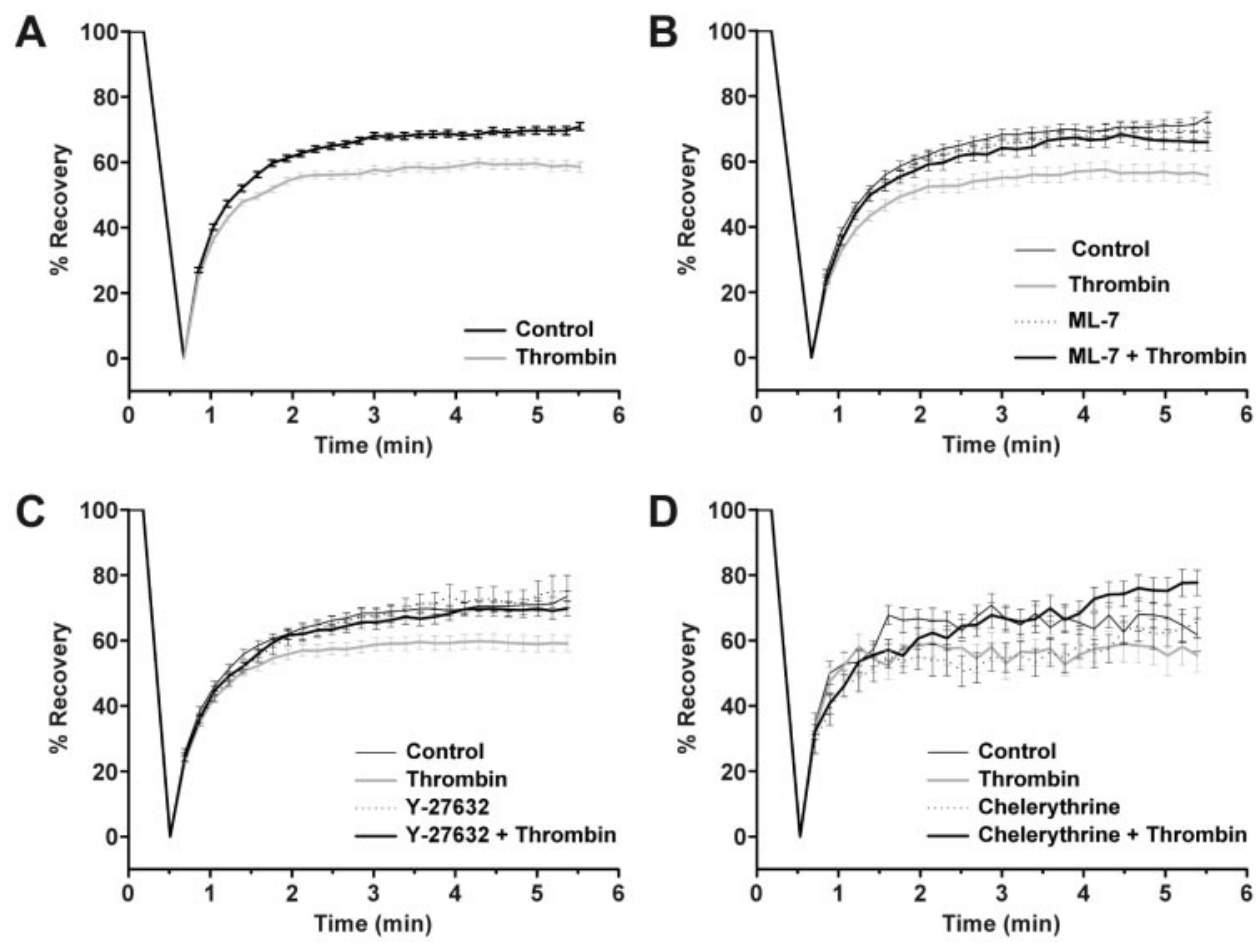

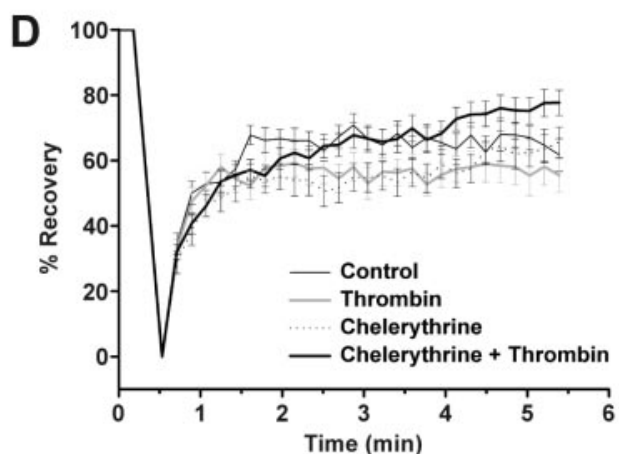

ARL-67156 was almost completely inhibited in the presence of thrombin (reduction of AA by 87\%). These experiments demonstrate the influence of thrombin on ATP-mediated PIC. Specifically, these findings suggest that the effect of thrombin is due to a block of ATP release.

We therefore investigated the effect of thrombin after treatment of the cells with the nucleotidases apyrase VI $(5 \mathrm{U} / \mathrm{mL})$ and apyrase VII $(5 \mathrm{U} / \mathrm{mL})$, to inhibit PIC via hydrolysis of ATP and adenosine diphosphate (ADP). The propagation of the $\mathrm{Ca}^{2+}$ wave is markedly reduced in the presence of these nucleotidases. ${ }^{17,18}$ In the presence of the nucleotidases, neither thrombin nor TRAP-6 had a significant effect on the AA of the $\mathrm{Ca}^{2+}$ wave $(N=20$; Fig. $8 \mathrm{~B})$. These experiments again indicate that thrombin exerts its effect mainly via PIC.

Effects of Gap26 and Flufenamic Acid in the Presence of ARL-67156. To investigate the effect of thrombin on pathways contributing to PIC other than Gap26-sensitive hemichannels, we compared the effects of the protease after pretreatment with Gap26 or flufenamic acid in a condition where PIC was maximized using ARL-67156. Under these conditions, thrombin failed to reduce the AA in cells pretreated with Gap26 (Fig. 9A, column 4 versus column 3). Furthermore, this AA was also not significantly different from the one obtained without pretreatment with Gap26 (Fig. 9A; column 4 versus column 2). These results demonstrate that thrombin exerts its effect via a Gap26-sensitive pathway, indicating the involvement of connexin hemichannels. Similar results were obtained with flufenamic acid ( $50 \mu \mathrm{M}$ for 30 minutes; $N=35$ ), which is also known to block hemichannels in BCECs ${ }^{17}$ and other cells, such as astrocytes, ${ }^{24}$ although the drug is not selective, because it is also known to inhibit $\mathrm{Cl}^{-}$channels ${ }^{24}$ (Fig. 9B). These results indicate that pathways other than connexin hemichannels do not contribute to the effect of thrombin on the $\mathrm{Ca}^{2+}$ wave propagation.

Dye Uptake Experiments. The sensitivity of the wave propagation to Gap26 demonstrated in our experiments, and similar findings reported previously, ${ }^{17,58}$ indicated the involvement of hemichannels in ATP release. As shown in previous studies, ${ }^{17}$ connexin hemichannels are significantly permeable to the hydrophilic dye $\mathrm{LY}$ in $\mathrm{Ca}^{2+}$-free solutions containing EGTA $(2 \mathrm{mM})$. To investigate whether thrombin inhibits hemichannel-mediated PIC, we examined the effects of thrombin $(2 \mathrm{U} / \mathrm{mL})$ and TRAP-6 $(10 \mu \mathrm{M}$; pretreatment for 30 minutes $)$ on LY uptake. As shown in Figure 10A, exposure to PAR-1 agonist (thrombin or TRAP- $6, N=10$ ) under $\mathrm{Ca}^{2+}$-free medium (containing $2 \mathrm{mM}$ EGTA and LY) led to complete inhibition of LY uptake. Furthermore, exposure to drugs which inhibit MLC phosphorylation overcame the effect of thrombin. Thus, when cells were pretreated with ML-7 (10 $\mu \mathrm{M}$ for 30 minutes, $N=4)$, Y-27632 (10 $\mu \mathrm{M}$ for 30 minutes, $N=3)$, or chelerythrine ( $5 \mu \mathrm{M}$ for 30 minutes, $N=3$ ), LY uptake was similar to control conditions (Figs. 10B, 10C, and 10D, respectively). These results indicate that PAR-1 activation blocked LY uptake rapidly, and therefore, we suggest that thrombin inhibits connexin hemichannels and hence the PIC pathway.

Effects on ATP Release. To study whether PAR-1 agonists inhibit ATP release on mechanical stimulation in BCECs, we measured extracellular ATP levels by the luciferin-luciferase technique. Thrombin ( $2 \mathrm{U} / \mathrm{mL}$ for 5 minutes) markedly reduced ATP release on mechanical stimulation (median reduction, $69 \% ; N=55$ ). The reduction by thrombin was only $9 \%$ after pretreatment with the PAR-1 antagonist $(10 \mu \mathrm{M}$ for 30 minutes; $N=3$ ), $23 \%$ in the presence of Y-27632 (10 $\mu \mathrm{M}$ for 30 minutes; $N=5$ ), and $20 \%$ in the presence of chelerythrine ( 5 $\mu \mathrm{M}$ for 30 minutes; $N=5)$. The PAR- 4 antagonist YD-3 $(50 \mu \mathrm{M}$ for 30 minutes; $N=3$ ) did not influence the effect of thrombin on ATP release. Similar to thrombin, TRAP-6 (10 $\mu \mathrm{M}$ for 30 minutes) caused a marked inhibition of ATP release on mechanical stimulation (median reduction of $50 \% ; N=16$ ).

\section{Discussion}

Intercellular $\mathrm{Ca}^{2+}$ wave propagation in response to a point mechanical stimulus is a distinct paradigm for investigating IC. ${ }^{28,59-61}$ In corneal endothelial cells, the intercellular wave 
propagation is dominated by PIC, ${ }^{17-19}$ mediated by ATP release through hemichannels. ${ }^{17-19}$ In this study, we investigated whether altered MLC phosphorylation influences GJIC and PIC in BCECs. Since thrombin has been shown to produce wellcharacterized and reproducible acute effects in terms of MLC phosphorylation, ${ }^{46,48,49}$ we examined its effect on GJIC and PIC in conjunction with a known set of agents that inhibit GJIC and PIC. ${ }^{17,18}$ The main findings of the present study are that thrombin brings about a very robust inhibition of the $\mathrm{Ca}^{2+}$ wave propagation through mechanisms linked to MLC phosphorylation and that the dominant effect of the protease is through inhibition of the ATP-dependent PIC.

\section{Effects of Thrombin: Dependence on PAR-1 Receptors}

To unravel the signaling pathway underlying inhibition of the $\mathrm{Ca}^{2+}$ wave highlighted in Figures 1 and 2, we explored the identity of the thrombin receptors that cause the effect. Experiments with PAR agonists (thrombin and TRAP-6) and antagonists ${ }^{56,57}$ provide clear evidence that the effect of thrombin is mediated through PAR-1 receptors (Figs. 3, 4). Independent experiments demonstrated that cells pretreated with thrombin showed an increase in $\left[\mathrm{Ca}^{2+}\right]_{\mathrm{i}}$ on exposure to exogenous ATP
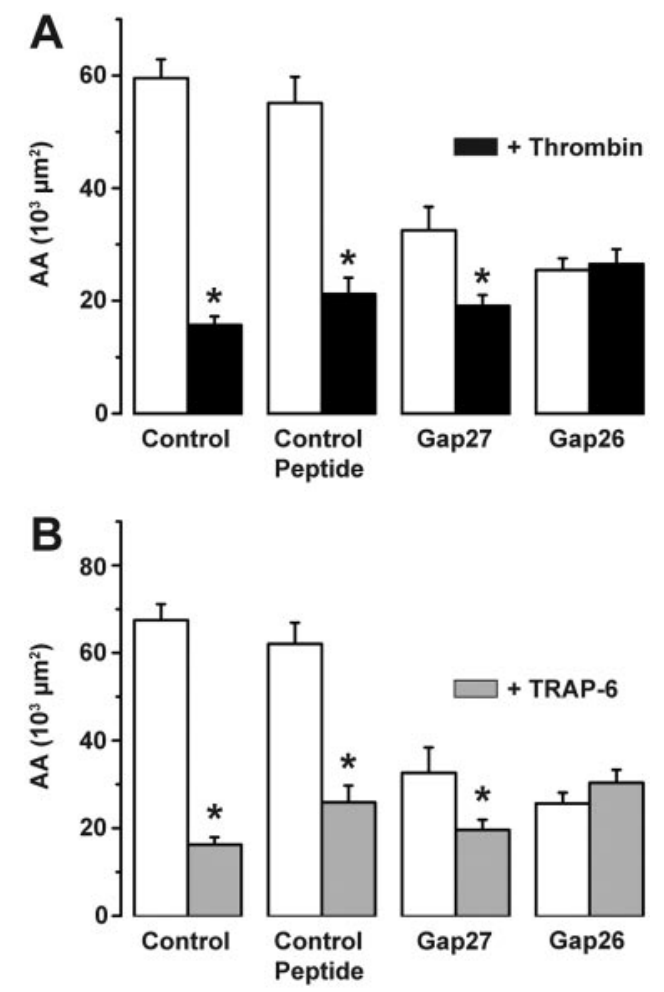

FIGURE 7. Effect of Gap27 and Gap26 on the reduction of AA induced by PAR-1 agonists. AA in BCECs were treated with thrombin $(2 \mathrm{U} / \mathrm{mL}$ for 5 minutes) or TRAP-6 (10 $\mu \mathrm{M}$ for 30 minutes) after incubation with connexin mimetic peptides, namely control peptide $(300 \mu \mathrm{M})$, Gap27 $(300 \mu \mathrm{M})$, or Gap26 $(300 \mu \mathrm{M})$ for 30 minutes. ( $\square$ ) AA in the absence of PAR-1 agonist. (A) In the presence of Gap27, thrombin caused a further decrease in AA, compared with Gap27 alone. In the presence of Gap26, thrombin did not cause a further decrease in AA, compared with Gap26 alone. AA in the presence of the control peptide plus thrombin is not significantly different from that in the presence of thrombin alone $(N=40)$. (B) Similar results were obtained with TRAP-6 $(N=25)$. ${ }^{*} P<0.001$ for comparison between AA in the presence versus absence of the PAR-1 agonist (i.e., comparison of $\mathbf{\square}$ or $\square$ with $\square$ in each condition).
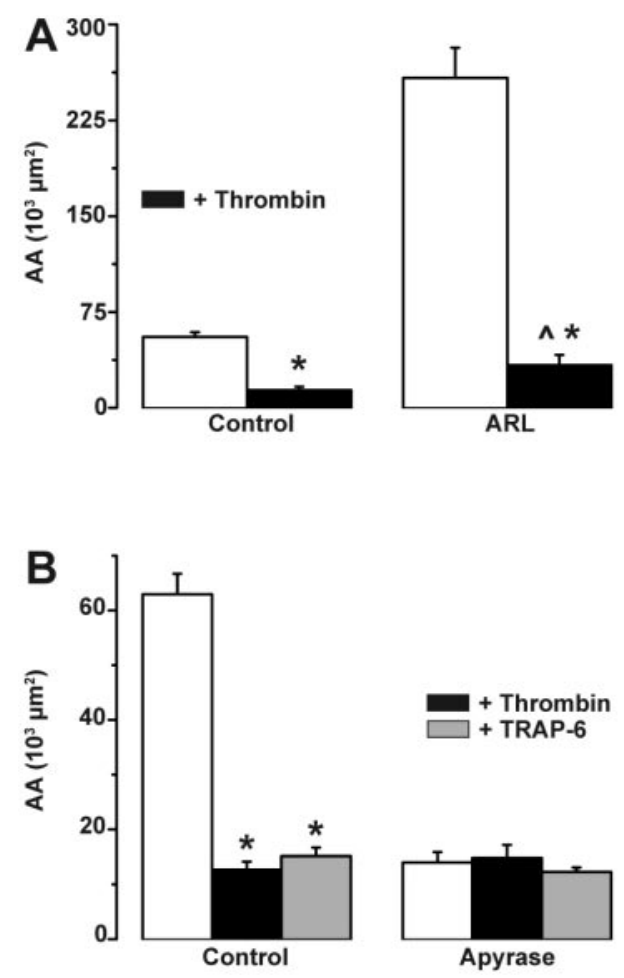

FIGURE 8. Effect of inhibition of ectonucleotidase activity and of exposure to exogenous nucleotidases on reduction of the AA induced by PAR-1 agonists. (A) Effect of thrombin ( $2 \mathrm{U} / \mathrm{mL}$ for 5 minutes) on AA in the control condition and in the presence of the selective ectonucleotidase inhibitor ARL-67156 (ARL; $100 \mu \mathrm{M}$ for 30 minutes). ( $\square$ ) AA in the absence of thrombin. In cells treated with ARL, thrombin caused a significant decrease in AA $(N=20)$. ${ }^{*} P<0.001$ for comparison between $\mathrm{AA}$ in the presence of thrombin versus AA in the absence of thrombin. ${ }^{\wedge} P<0.001$ for comparison of AA in cells treated with thrombin with and without ARL. (B) Effect of PAR-1-agonists on AA under control condition and in the presence of exogenous apyrases. Treatment of the cells with apyrase VI $(5 \mathrm{U} / \mathrm{mL})$ and apyrase VII $(5$ $\mathrm{U} / \mathrm{mL}$ ) for 30 minutes decreased AA. In this condition, neither thrombin nor TRAP- 6 caused a further decrease in AA. ${ }^{*} P<0.001$ for comparison of AA in the presence of thrombin or TRAP-6 against the control (i.e., comparison of $\square$ or $\square$ with $\square$ in each condition).

that was not significantly different from that in untreated cells. This suggests that thrombin had no effect on the $\mathrm{P} 2$ receptors and their signaling pathway involved in the $\mathrm{Ca}^{2+}$ wave propagation, or on the intracellular $\mathrm{Ca}^{2+}$ stores. Moreover, the effect of TRAP-6 excluded that the inhibitory effect of thrombin on the wave propagation is mediated by proteolytic activity on cell surface molecules other than PAR-1 (Fig. 4A).

\section{Effects of Thrombin on GJIC and PIC:} Dependence on MLC Phosphorylation

As shown in our previous studies, ${ }^{46,48,49}$ thrombin induces MLC phosphorylation, leading to a breakdown of barrier integrity in BCECs. The pathways involved are illustrated in Figure 11. Our observation that the effect of thrombin on $\mathrm{Ca}^{2+}$ wave propagation is suppressed by Y-27632, chelerythrine and ML-7 (shown in Fig. 5), is an indication of an involvement of MLC phosphorylation in intercellular communication. Specifically, as shown in Figure 11, Y-27632, chelerythrine and ML-7 inhibit Rho kinase, PKC, and MLCK, respectively, each of which affect MLC phosphorylation.

Effect on GJIC. FRAP protocol ${ }^{19}$ is quantitative and hence we used it to assess the effect of thrombin on GJIC. As shown 

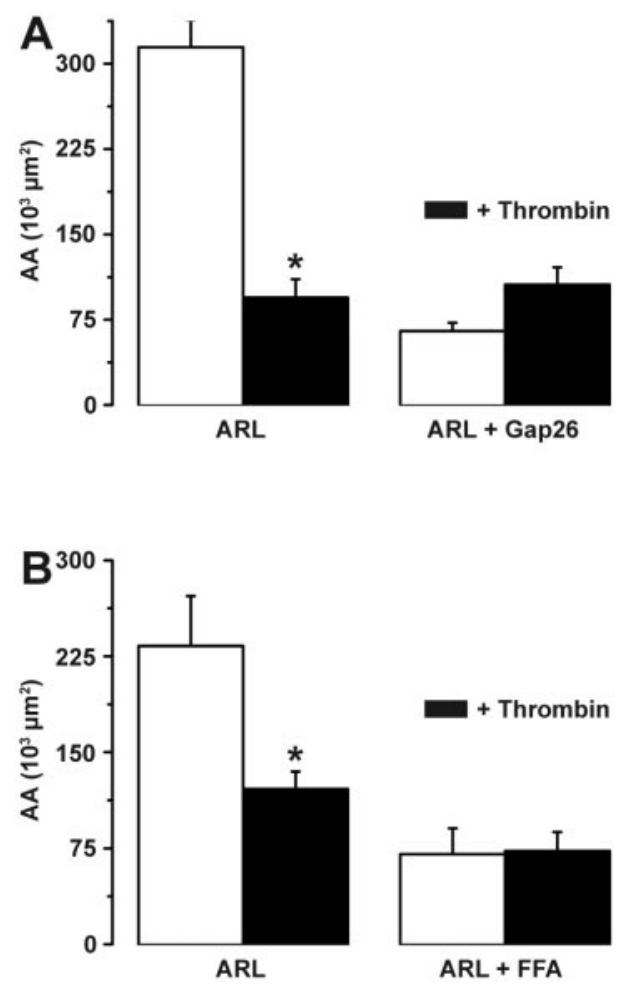

FIGURE 9. Effect of Gap26 and flufenamic acid on reduction of AA induced by thrombin in the presence of ARL-67156. Cells were treated with thrombin ( $2 \mathrm{U} / \mathrm{mL}$ for 5 minutes) after incubation with ARL-67156 (ARL, $100 \mu \mathrm{M}$ for 30 minutes) and with the combination of ARL with either Gap26 (300 $\mu \mathrm{M}$ for 30 minutes) or flufenamic acid (FFA; $50 \mu \mathrm{M}$ for 30 minutes). ( $\square$ ) AA in the absence of PAR-1 agonist (control). (A) AA in the presence of ARL and Gap26 and thrombin is not significantly different from that in the presence of ARL and Gap26 alone $(N=40)$. (B) Similar results were obtained with FFA $(N=35)$. ${ }^{*} P<0.001$ for comparison between AA in the presence versus absence of the PAR-1 agonist in contemporaneous experiments.

in Figure 6, in the FRAP experiments thrombin inhibited GJIC, although the reduction was limited $(\sim 15 \%)$. Furthermore, in the presence of the selective protein kinase inhibitors, the reduction in the fluorescence recovery was suppressed. This indicates that GJIC is inhibited in response to MLC phosphorylation.

Effect on PIC. The large reduction of the AA in response to Gap26 (known to block connexin hemichannels; Fig. 7) or to apyrases (Fig. 8B) clearly highlights that PIC, mediated by ATP release through hemichannels, dominates the wave propagation in BCECs. When the hydrolysis of the released ATP is prevented using ARL-67156, the $\mathrm{Ca}^{2+}$ wave propagation is significantly enhanced. As shown in Figure 8A, this increase of the AA is almost completely abolished by thrombin, implying that thrombin has a major inhibitory effect on PIC.

The significant effect of thrombin on PIC led us to explore further the effects of MLC phosphorylation on the activity of hemichannels. We first examined whether hemichannel-mediated ATP release in response to mechanical stimulation ${ }^{17}$ could be blocked by agents that affect MLC phosphorylation. The ATP release was inhibited by thrombin, and moreover, this effect was suppressed by the kinase inhibitors (ML-7, chelerythrine, and Y-27632). Our second approach was to confirm whether hemichannels are influenced by MLC phosphorylation, based on LY uptake in a $\mathrm{Ca}^{2+}$-free medium, which occurs through hemichannels. ${ }^{17}$ As shown in Figure 10, LY uptake is also inhibited by thrombin, and this effect was also over- come by the kinase inhibitors. Thus, PIC, through hemichannel-mediated ATP release, is inhibited by MLC phosphorylation. Cotrina et al. ${ }^{28}$ also have implicated actin cytoskeleton in the propagation of $\mathrm{MS} \mathrm{Ca}^{2+}$ waves in astrocytes. However, in contrast to our findings in BCECs, they observed inhibition of the intercellular $\mathrm{Ca}^{2+}$ wave propagation in response to ML-7.

The above observations led us to conclude that the effect of thrombin on the $\mathrm{Ca}^{2+}$ wave propagation is largely through inhibition of PIC.

\section{Effects of Thrombin: Role of Cortical Actin}

Gap junctions are located in close proximity to the tight and adherens junctions, and share common linker proteins that bind to the actin cytoskeleton. ${ }^{20,62-64}$ The adherens junctions, by promoting cell-cell adhesion, stabilize the interactions of transmembrane proteins of the tight junction complex (i.e., claudin, occludin, and junctional adhesion molecule) that are essential to occlude the paracellular space. ${ }^{65,66}$ This tethering force brought on by the adherens junctions is opposed by the centripetal forces produced by an increase in contractility of the cortical actin cytoskeleton. ${ }^{36,39,40}$ Thus, agents that raise contractility of the actin cytoskeleton are known to breakdown the barrier integrity of cellular monolayers. Recent studies on the corneal endothelium also reflect these findings. ${ }^{46,48,49}$ When BCECs were exposed to thrombin, a significant increase in the paracellular permeability was noticed concomitant with a disruption of the cortical actin. ${ }^{46}$

These observations suggest that agents that can increase MLC phosphorylation, could disrupt gap junctions and thereby affect GJIC, because in nonmuscle cells, the primary mechanism of increasing contractility of the actin cytoskeleton is through an increase in MLC phosphorylation. ${ }^{35,39-41}$ Therefore, our findings suggest an involvement of increased contractility of the actin cytoskeleton in the inhibition of gap junctions by thrombin (Fig. 11). In agreement with the above hypothesis, our results show a significant, although small, inhibition of GJIC in response to increased MLC phosphorylation.

Although much less is known about the effects of an altered actin cytoskeleton on hemichannels, it is possible that connexon trafficking, internalization, and gating of hemichannels could be influenced by the cortical actin cytoskeleton through altered scaffolding, or altered signaling via direct protein-protein interactions or downstream transduction pathways. ${ }^{20}$

\section{Potential Effects of MLC Phosphorylation on Cx43 and ZO-1 Interactions}

As noted in Figure 11, a key mechanism toward MLC phosphorylation that is upregulated by thrombin is the activation of the RhoA-Rho kinase axis. ${ }^{46,48,49}$ Thus, an inhibition of the $\mathrm{Ca}^{2+}$ wave secondary to the thrombin-induced MLC phosphorylation and its prevention by the Rho kinase inhibitor Y-27632 (Figs. 5, 6) suggest an involvement of the RhoA-Rho kinase axis in GJIC and PIC. In line with this conclusion, Anderson et al. ${ }^{9}$ have reported that inhibition of Rho kinase in corneal epithelial cells enhances dye coupling. Rouach et al. ${ }^{67}$ demonstrated RhoA-dependent inhibition of GJIC by S1P (sphingosine-1phosphate), based on dye coupling and electrophysiologic experiments.

In other studies on the effect of thrombin and other GPCR agonists, inhibition of GJIC by tyrosine phosphorylation of Cx43 has been shown. ${ }^{68-70}$ Specifically, the nonreceptor tyrosine kinase Src was implicated in acute reduction of GJIC, and this effect was shown to be independent of the RhoA-Rho 
A Control

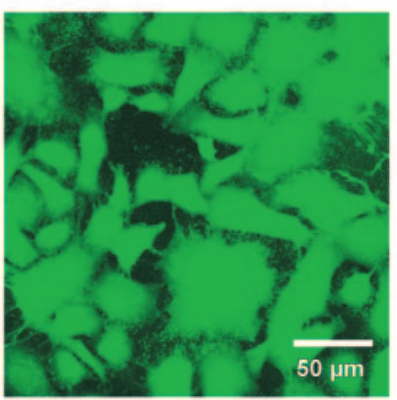

B

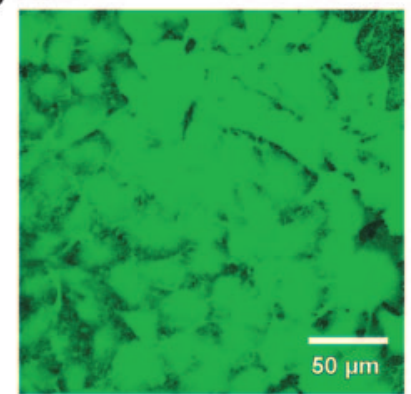

$C^{\text {Y-27632 }}$

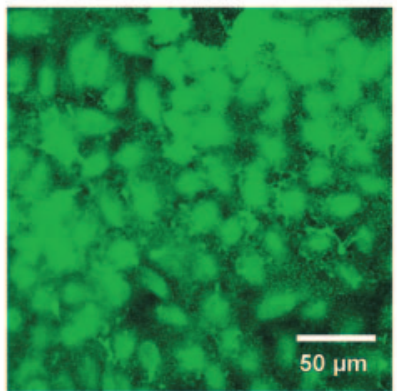

D Chelerythrine

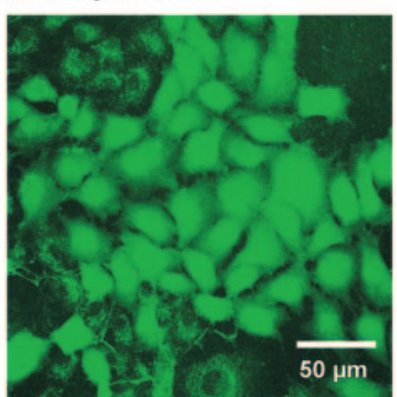

Thrombin

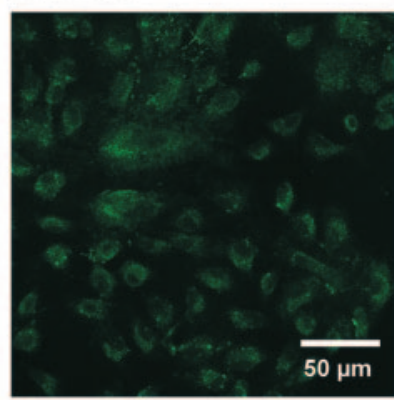

ML-7 + Thrombin

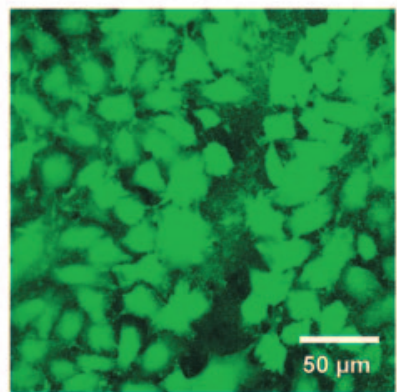

Y-27632 + Thrombin

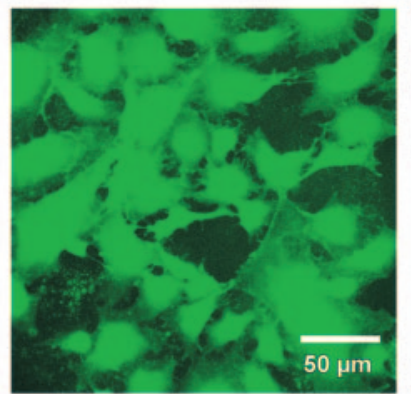

Chelerythrine + Thrombin

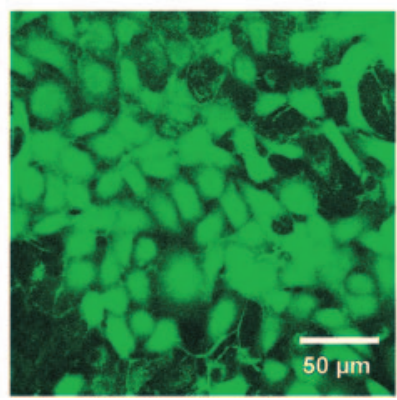

TRAP-6

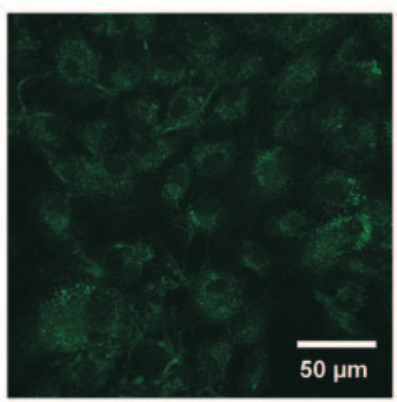

ML-7 + TRAP-6

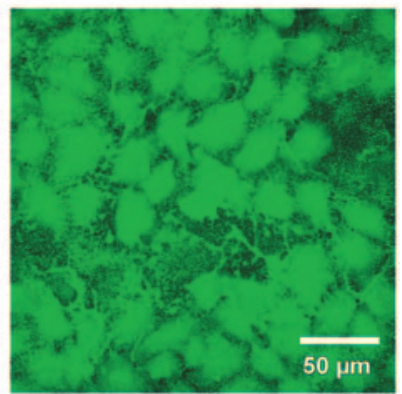

Y-27632 + TRAP-6

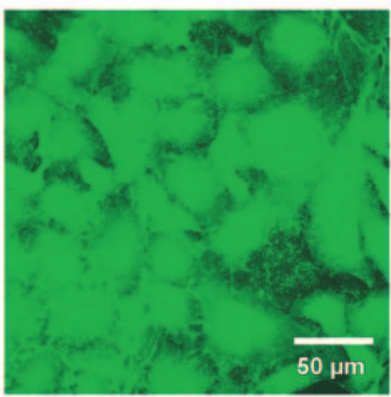

Chelerythrine + TRAP-6

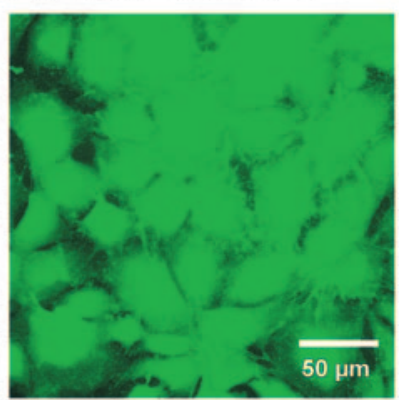

FIGURE 10. Effect of thrombin, TRAP-6, Y-27632, and ML-7 on LY uptake in $\mathrm{Ca}^{2+}$-free solutions. Cells were exposed to the fluorescent dye LY (2.5\% for 5 minutes) in $\mathrm{Ca}^{2+}$-free solution containing $2 \mathrm{mM}$ EGTA. (A) Uptake of LY in the control condition. The uptake of the dye was blocked in cells treated with thrombin ( $2 \mathrm{U} / \mathrm{mL}$ for 5 minutes) or TRAP-6 (10 $\mu \mathrm{M}$ for 30 minutes). (B) The MLCK inhibitor ML-7, (C) the Rho kinase inhibitor Y-27632, and (D) the PKC inhibitor chelerythrine all inhibited the effect of thrombin or TRAP-6 on dye uptake.

kinase pathway. ${ }^{68,70}$ However, it has been shown that this effect of Src disrupts the interaction between ZO-1 and $\mathrm{Cx} 43$, reducing the stability of $\mathrm{Cx} 43$ at the cell surface. ${ }^{71}$ Furthermore, a recent study showed that MLCK-mediated MLC phosphorylation brings about a structural separation of ZO-1 and occludin from the actin cytoskeleton ${ }^{71}$ In this context, Cx43, which is known to interact with ZO-1 in several cell types, is also expressed in corneal endothelial cells, ${ }^{19}$ and such an interaction is implicated in connexin trafficking and internalization and accretion at gap junctions. ${ }^{20,72}$ However, taking into account the finding that thrombin inhibits $\mathrm{Ca}^{2+}$ wave propagation, FRAP and dye uptake within minutes (Fig. 10), we speculate that thrombin-induced redistribution of ZO-1, secondary to MLC phosphorylation, can also affect gating of the $\mathrm{Cx} 43$-dependent hemichannels and gap junctions.

\section{Physiological Significance in the Corneal Endothelium}

Our observations highlight the influence of MLC phosphorylation and contractility of the actin cytoskeleton on IC in the corneal endothelium. Although this is partly reminiscent of the role of the actin cytoskeleton in the loss of barrier integrity, ${ }^{46,48,49}$ the block of hemichannels involved in the PIC suggests the importance of the disposition of cortical 
Figure 11. Postulated mechanisms underlying inhibition of intercellular $\mathrm{Ca}^{2+}$ wave in corneal endothelial cells through activation of PAR-1 receptors. Thrombin, a serine protease, cleaves off an exodomain of the receptor and thereby unmasks a tethered ligand. This evokes activation of $\mathrm{G}_{\alpha \mathrm{q} / 11}$ and $\mathrm{G}_{\alpha 12 / 13}$ signaling. $\mathrm{G}_{\alpha q / 11}$ is responsible for $\left[\mathrm{Ca}^{2+}\right]_{\mathrm{i}}$-mediated activation of MLCK. PKC promotes MLC phosphorylation by inhibiting MLCP and may also participate through cross-talk with RhoA signaling (dashed lines). Activated $\mathrm{G}_{\alpha 12 / 13}$ mobilizes RhoGEFs which evoke activation of the RhoARho kinase axis. Rho kinase inhibits MLCP and thereby promotes MLC phosphorylation. Increased MLC phosphorylation leads to increased contractility of the actin cytoskeleton as well as disruption of the organization of the cortical actin. While a loss in the tethering forces is shown to break down the barrier integrity, our FRAP experiments demonstrated loss of GJIC as well. The block of dye uptake and ATP release, along with the significant reduction in the $\mathrm{Ca}^{2+}$ wave propagation, suggest that a disruption in the cortical actin inhibits hemichannel activity and hence PIC. ML-7, chelerythrine (Ch), and Y-27632 are inhibitors of MLCK, PKC, and Rho-kinase, respectively.
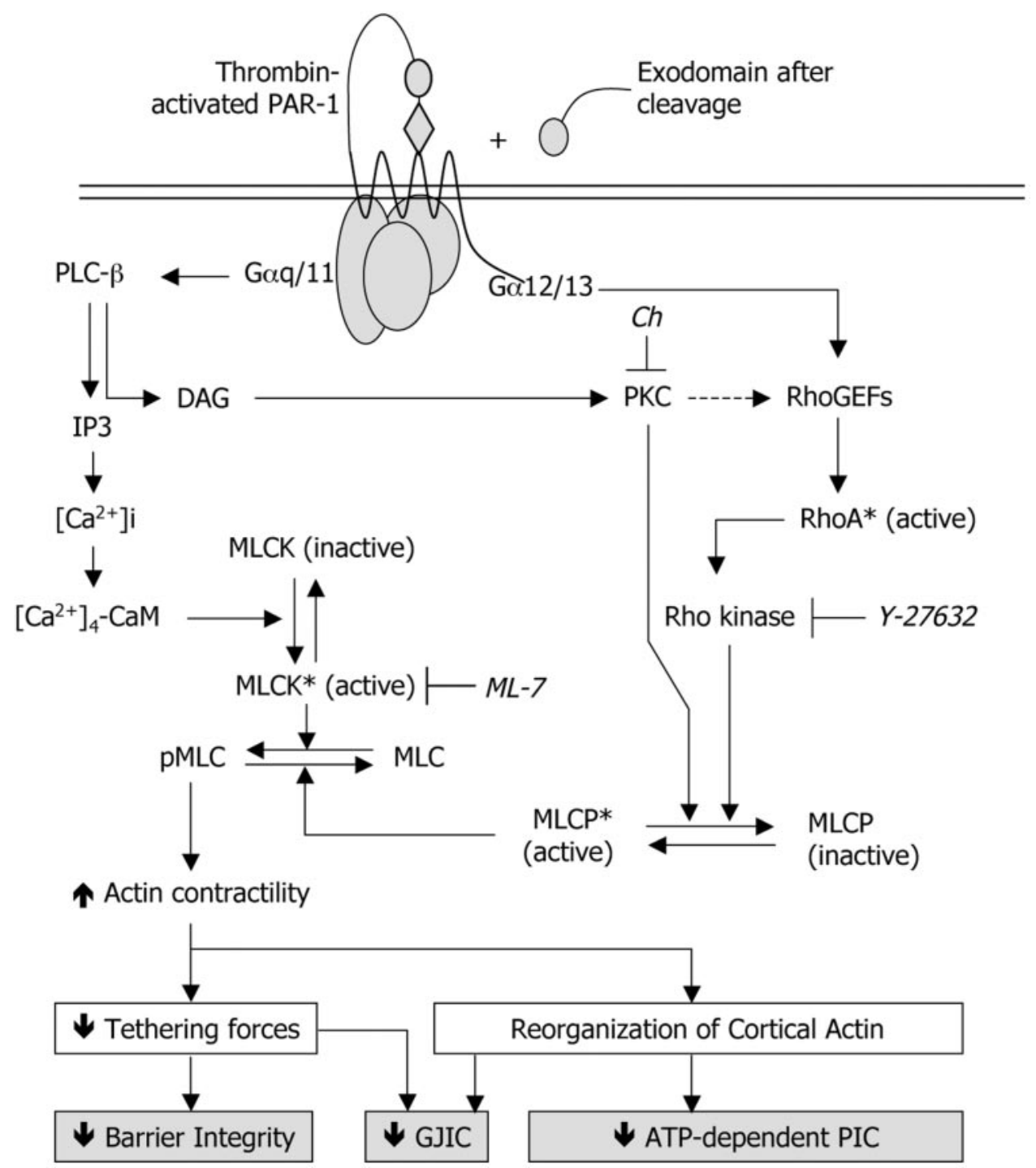

actin in the function of the endothelium in addition to the role of the tethering forces. In situations of inflammatory stress, which usually result in MLC phosphorylation, ${ }^{73-76}$ blockage of the hemichannels can be thought of as being a defense mechanism. Thus, such a blockade would limit IC and prevent potential bystander effects, ${ }^{77,78}$ through limiting the release of signaling molecules. In addition, it is plausible that hemichannel blockage can prevent disturbances of intracellular homeostasis by solute entry/loss through the channels. Furthermore, the influence of the cortical actin cytoskeleton organization and/or contractility on hemichannels suggests their altered activity in response to hypoxia and aging, since, under these conditions, the corneal endothelial cells show significant alterations in the actin cytoskeleton, as suggested by polymegathism and polymorphism.

\section{Acknowledgments}

The authors thank Wendy Janssens for technical assistance and help with the experiments and Hans Deckmyn, Marc Hoylaerts, Hugo Ceulemans, and Jozef Arnout for critical discussions.

\section{References}

1. Joyce NC. Proliferative capacity of the corneal endothelium. Prog Retin Eye Res. 2003;22:359-389.

2. George AJ, Larkin DF. Corneal transplantation: the forgotten graft. Am J Transplant. 2004;4:678-685.

3. Riley M. Pump and leak in regulation of fluid transport in rabbit cornea. Curr Eye Res. 1985;4:371-376.

4. Riley MV, Winkler BS, Starnes CA, et al. Regulation of corneal endothelial barrier function by adenosine, cyclic AMP, and protein kinases. Invest Ophthalmol Vis Sci. 1998;39:2076-2084.

5. Edelhauser HF. The resiliency of the corneal endothelium to refractive and intraocular surgery. Cornea. 2000;19:263-273.

6. Williams KK, Watsky MA. Bicarbonate promotes dye coupling in the epithelium and endothelium of the rabbit cornea. Curr Eye Res. 2004;28:109-120.

7. Hernandez Galindo EE, Theiss C, Steuhl KP, Meller D. Gap junctional communication in microinjected human limbal and peripheral corneal epithelial cells cultured on intact amniotic membrane. Exp Eye Res. 2003;76:303-314.

8. Williams K, Watsky M. Gap junctional communication in the human corneal endothelium and epithelium. Curr Eye Res. 2002;25:29-36.

9. Anderson SC, Stone C, Tkach L, SundarRaj N. Rho and Rho-kinase (ROCK) signaling in adherens and gap junction assembly in corneal epithelium. Invest Ophthalmol Vis Sci. 2002;43:978-986. 
10. Joyce NC, Harris DL, Zieske JD. Mitotic inhibition of corneal endothelium in neonatal rats. Invest Ophthalmol Vis Sci. 1998;39: 2572-2583.

11. Klepeis VE, Weinger I, Kaczmarek E, Trinkaus-Randall V. P2Y receptors play a critical role in epithelial cell communication and migration. J Cell Biochem. 2004;93:1115-1133.

12. Klepeis VE, Cornell-Bell A, Trinkaus-Randall V. Growth factors but not gap junctions play a role in injury-induced $\mathrm{Ca}^{2+}$ waves in epithelial cells. J Cell Sci. 2001;114:4185-4195.

13. Laux-Fenton WT, Donaldson PJ, Kistler J, Green CR. Connexin expression patterns in the rat cornea: molecular evidence for communication compartments. Cornea. 2003;22:457-464.

14. Rae JL, Lewno AW, Cooper K, Gates P. Dye and electrical coupling between cells of the rabbit corneal endothelium. Curr Eye Res. 1989;8:859-869.

15. Watsky MA, Rae JL. Dye coupling in the corneal endothelium: effects of ouabain and extracellular calcium removal. Cell Tissue Res. 1992;269:57-63.

16. Williams KK, Watsky MA. Dye spread through gap junctions in the corneal epithelium of the rabbit. Curr Eye Res. 1997;16:445-452.

17. Gomes P, Srinivas SP, Van Driessche W, et al. ATP release through connexin hemichannels in corneal endothelial cells. Invest Ophthalmol Vis Sci. 2005;46:1208-1218.

18. Gomes P, Srinivas SP, Vereecke J, Himpens B. ATP-dependent paracrine intercellular communication in cultured bovine corneal endothelial cells. Invest Ophthalmol Vis Sci. 2005;46:104-113.

19. Gomes P, Srinivas SP, Vereecke J, Himpens B. Gap junctional intercellular communication in bovine corneal endothelial cells. Exp Eye Res. 2006;83;1225-1237.

20. Laird DW. Life cycle of connexins in health and disease. Biochem J. 2006;394:527-543.

21. Cotrina ML, Lin JH, Lopez-Garcia JC, et al. ATP-mediated glia signaling. J Neurosci. 2000;20:2835-2844.

22. Pearson RA, Dale N, Llaudet E, Mobbs P. ATP released via gap junction hemichannels from the pigment epithelium regulates neural retinal progenitor proliferation. Neuron. 2005;46:731-744.

23. Braet K, Vandamme W, Martin PE, et al. Photoliberating inositol1,4,5-trisphosphate triggers ATP release that is blocked by the connexin mimetic peptide gap 26. Cell Calcium. 2003;33:37-48.

24. Stout CE, Costantin JL, Naus CC, Charles AC. Intercellular calcium signaling in astrocytes via ATP release through connexin hemichannels. J Biol Chem. 2002;277:10482-10488.

25. Cherian PP, Cheng B, Gu S, et al. Effects of mechanical strain on the function of gap junctions in osteocytes are mediated through the prostaglandin EP2 receptor. J Biol Chem. 2003;278:43146156.

26. Laird DW. Connexin phosphorylation as a regulatory event linked to gap junction internalization and degradation. Biochim Biophys Acta. 2005;1711:172-182.

27. Duffy HS, Ashton AW, O'Donnell P, et al. Regulation of connexin 43 protein complexes by intracellular acidification. Circ Res. 2004;94:215-222.

28. Cotrina ML, Lin JH, Nedergaard M. Cytoskeletal assembly and ATP release regulate astrocytic calcium signaling. J Neurosci. 1998;18: 8794-8804.

29. Figueroa XF, Alvina K, Martinez AD, et al. Histamine reduces gap junctional communication of human tonsil high endothelial cells in culture. Microvasc Res. 2004;68:247-257.

30. Giessmann D, Theiss C, Breipohl W, Meller K. Decreased gap junctional communication in neurobiotin microinjected lens epithelial cells after taxol treatment. Anat Embryol (Berl). 2005;209: 391- 400 .

31. Saffitz JE, Douglas P. Zipes Lecture. Biology and pathobiology of cardiac connexins: from cell to bedside. Heart Rhythm. 2006;3: 102-107.

32. Theiss C, Meller K. Microinjected anti-actin antibodies decrease gap junctional intercellular communication in cultured astrocytes. Exp Cell Res. 2002;281:197-204.

33. Thomas T, Jordan K, Laird DW. Role of cytoskeletal elements in the recruitment of $\mathrm{Cx} 43-\mathrm{GFP}$ and $\mathrm{Cx} 26-\mathrm{YFP}$ into gap junctions. Cell Commun Adbes. 2001;8:231-236.
34. Guo Y, Martinez-Williams C, Rannels DE. Gap junction-microtubule associations in rat alveolar epithelial cells. Am J Physiol. 2003;285:L1213-L1221.

35. Dudek SM, Garcia JG. Cytoskeletal regulation of pulmonary vascular permeability. J Appl Physiol. 2001;91:1487-1500.

36. Garcia JG, Davis HW, Patterson CE. Regulation of endothelial cell gap formation and barrier dysfunction: role of myosin light chain phosphorylation. J Cell Physiol. 1995;163:510-522.

37. Patterson CE, Lum H, Schaphorst KL, et al. Regulation of endothelial barrier function by the cAMP-dependent protein kinase. Endothelium. 2000;7:287-308.

38. Shen L, Black ED, Witkowski ED, et al. Myosin light chain phosphorylation regulates barrier function by remodeling tight junction structure. J Cell Sci. 2006;119:2095-2106.

39. Turner JR. 'Putting the squeeze' on the tight junction: understanding cytoskeletal regulation. Semin Cell Dev Biol. 2000;11:301308.

40. Turner JR, Rill BK, Carlson SL, et al. Physiological regulation of epithelial tight junctions is associated with myosin light-chain phosphorylation. Am J Physiol. 1997;273:C1378-C1385.

41. Kamm KE, Stull JT. Dedicated myosin light chain kinases with diverse cellular functions. $J$ Biol Chem. 2001;276:4527-4530.

42. Somlyo AP, Somlyo AV. $\mathrm{Ca}^{2+}$ sensitivity of smooth muscle and nonmuscle myosin II: modulated by $\mathrm{G}$ proteins, kinases, and myosin phosphatase. Physiol Rev. 2003;83:1325-1358.

43. Leybaert L, Braet K, Vandamme W, et al. Connexin channels, connexin mimetic peptides and ATP release. Cell Commun Adbes. 2003;10:251-257.

44. Saez JC, Retamal MA, Basilio D, et al. Connexin-based gap junction hemichannels: gating mechanisms. Biochim Biophys Acta. 2005; 1711:215-224.

45. Tran Van Nhieu G, Clair C, Bruzzone R, et al. Connexin-dependent inter-cellular communication increases invasion and dissemination of Shigella in epithelial cells. Nat Cell Biol. 2003;5:720-726.

46. Satpathy M, Gallagher P, Lizotte-Waniewski M, Srinivas SP. Thrombin-induced phosphorylation of the regulatory light chain of myosin II in cultured bovine corneal endothelial cells. Exp Eye Res. 2004;79:477-486.

47. Bogatcheva NV, Garcia JG, Verin AD. Molecular mechanisms of thrombin-induced endothelial cell permeability. Biochemistry (Mosc). 2002;67:75-84

48. Satpathy M, Gallagher P, Jin Y, Srinivas SP. Extracellular ATP opposes thrombin-induced myosin light chain phosphorylation and loss of barrier integrity in corneal endothelial cells. Exp Eye Res. 2005;81:183-192.

49. Srinivas SP, Satpathy M, Gallagher P, et al. Adenosine induces dephosphorylation of myosin II regulatory light chain in cultured bovine corneal endothelial cells. Exp Eye Res. 2004;79:543-551.

50. Srinivas SP, Yeh JC, Ong A, Bonanno JA. $\mathrm{Ca}^{2+}$ mobilization in bovine corneal endothelial cells by $\mathrm{P} 2$ purinergic receptors. Curr Eye Res. 1998;17:994-1004.

51. Jans D, Srinivas SP, Waelkens E, et al. Hypotonic treatment evokes biphasic ATP release across the basolateral membrane of cultured renal epithelia (A6). J Physiol. 2002;545:543-555.

52. Coughlin SR. Thrombin signalling and protease-activated receptors. Nature. 2000;407:258-264.

53. Cocks TM, Moffatt JD. Protease-activated receptors: sentries for inflammation? Trends Pharmacol Sci. 2000;21:103-108.

54. Coughlin SR. Protease-activated receptors in hemostasis, thrombosis and vascular biology. J Thromb Haemost. 2005;3:1800-1814.

55. Macfarlane SR, Seatter MJ, Kanke T, et al. Proteinase-activated receptors. Pharmacol Rev. 2001;53:245-282.

56. Seiler SM, Peluso M, Michel IM, et al. Inhibition of thrombin and SFLLR-peptide stimulation of platelet aggregation, phospholipase A2 and $\mathrm{Na}^{+} / \mathrm{H}^{+}$exchange by a thrombin receptor antagonist. Biochem Pharmacol. 1995;49:519-528.

57. Peng CY, Pan SL, Guh JH, et al. The indazole derivative YD-3 inhibits thrombin-induced vascular smooth muscle cell proliferation and attenuates intimal thickening after balloon injury. Thromb Haemost. 2004;92:1232-1239. 
58. Evans WH, De Vuyst E, Leybaert L. The gap junction cellular internet: connexin hemichannels enter the signalling limelight. Biochem J. 2006;397:1-14.

59. Boitano S, Evans WH. Connexin mimetic peptides reversibly inhibit $\mathrm{Ca}^{2+}$ signaling through gap junctions in airway cells. Am J Physiol. 2000;279:L623-L630.

60. Isakson $\mathrm{BE}$, Evans $\mathrm{WH}$, Boitano $\mathrm{S}$. Intercellular $\mathrm{Ca}^{2+}$ signaling in alveolar epithelial cells through gap junctions and by extracellular ATP. Am J Physiol. 2001;280:L221-L228.

61. Newman EA. Propagation of intercellular calcium waves in retinal astrocytes and Muller cells. J Neurosci. 2001;21:2215-2223.

62. Laing JG, Chou BC, Steinberg TH. ZO-1 alters the plasma membrane localization and function of $\mathrm{Cx} 43$ in osteoblastic cells. $J$ Cell Sci. 2005;118:2167-2176.

63. Zhu C, Barker RJ, Hunter AW, et al. Quantitative analysis of ZO-1 colocalization with $\mathrm{Cx} 43$ gap junction plaques in cultures of rat neonatal cardiomyocytes. Microsc Microanal. 2005;11:244-248.

64. Kausalya PJ, Reichert M, Hunziker W. Connexin 45 directly binds to ZO-1 and localizes to the tight junction region in epithelial MDCK cells. FEBS Lett. 2001;505:92-96.

65. Bruewer M, Hopkins AM, Hobert ME, et al. RhoA, Rac1, and Cdc42 exert distinct effects on epithelial barrier via selective structural and biochemical modulation of junctional proteins and F-actin. Am J Physiol. 2004;287:C327-C335.

66. Stevenson BR. Understanding tight junction clinical physiology at the molecular level. J Clin Invest. 1999;104:3-4.

67. Rouach N, Pebay A, Meme W, et al. S1P inhibits gap junctions in astrocytes: involvement of $\mathrm{G}$ and Rho GTPase/ROCK. Eur J Neurosci. 2006;23:1453-1464.

68. Postma FR, Hengeveld T, Alblas J, et al. Acute loss of cell-cell communication caused by $\mathrm{G}$ protein-coupled receptors: a critical role for c-Src. J Cell Biol. 1998;140:1199-1209.

69. Giepmans BN, Hengeveld T, Postma FR, Moolenaar WH. Interaction of c-Src with gap junction protein connexin-43: role in the regulation of cell-cell communication. J Biol Chem. 2001;276: $8544-8549$.

70. Giepmans BN, Feiken E, Gebbink MF, Moolenaar WH. Association of connexin 43 with a receptor protein tyrosine phosphatase. Cell Commun Adbes. 2003;10:201-205.

71. Toyofuku T, Akamatsu Y, Zhang H, et al. c-Src regulates the interaction between connexin- 43 and $\mathrm{ZO}-1$ in cardiac myocytes. J Biol Chem. 2001;276:1780-1788.

72. Lauf U, Giepmans BN, Lopez $\mathrm{P}$, et al. Dynamic trafficking and delivery of connexons to the plasma membrane and accretion to gap junctions in living cells. Proc Natl Acad Sci USA. 2002;99: 10446-10451.

73. Shen L, Turner JR. Role of epithelial cells in initiation and propagation of intestinal inflammation: eliminating the static: tight junction dynamics exposed. Am J Physiol. 2006;290: G577-G582.

74. Blair SA, Kane SV, Clayburgh DR, Turner JR. Epithelial myosin light chain kinase expression and activity are upregulated in inflammatory bowel disease. Lab Invest. 2006;86:191-201.

75. Utech M, Ivanov AI, Samarin SN, et al. Mechanism of IFN-gammainduced endocytosis of tight junction proteins: myosin II-dependent vacuolarization of the apical plasma membrane. Mol Biol Cell. 2005;16:5040-5052.

76. Wang F, Graham WV, Wang Y, et al. Interferon-gamma and tumor necrosis factor-alpha synergize to induce intestinal epithelial barrier dysfunction by up-regulating myosin light chain kinase expression. Am J Patbol. 2005;166:409-419.

77. Shao C, Furusawa Y, Aoki M, Ando K. Role of gap junctional intercellular communication in radiation-induced bystander effects in human fibroblasts. Radiat Res. 2003;160:318-323.

78. Andrade-Rozental AF, Rozental R, Hopperstad MG, et al. Gap junctions: the "kiss of death" and the "kiss of life". Brain Res Brain Res Rev. 2000;32:308-315. 